\title{
MicroRNA let-7d-5p rescues ovarian cancer cell apoptosis and restores chemosensitivity by regulating the p53 signaling pathway via HMGA1
}

\author{
YAN-NAN CHEN, CHEN-CHEN REN, LI YANG, MAN-MAN NAI, \\ YI-MING XU, FENG ZHANG and YAN LIU \\ Department of Obstetrics and Gynecology, The Third Affiliated Hospital of Zhengzhou University, \\ Zhengzhou, Henan 450052, P.R. China
}

Received May 4, 2018; Accepted October 4, 2018

DOI: 10.3892/ijo.2019.4731

\begin{abstract}
Ovarian cancer (OC) is the gynecological malignancy type with the highest mortality rate in females. The regulatory effect of microRNAs (miRs) on their target genes serves a key role in tumor development. Therefore, in the present study, whether miR let-7d-5p targeting high mobility group A1 (HMGA1) regulated biological characteristics and chemosensitivity of $\mathrm{OC}$ cells by mediating the p53 signaling pathway was investigated. The let-7d-5p level was detected in OC tissues and adjacent normal tissues, followed by detection in OC cell lines SKOV3, A2780, OVCAR-3 and CaOV3, and human normal ovarian epithelial cell line (IOSE-80), in order to select the $\mathrm{OC}$ cell line for the following experiments. Subsequently, OC cells were treated with the let-7d-5p mimic, siHMGA1 and Tenovin-1. The targeting association between let-7d-5p and HMGA1 was then examined, and the OC cell viability, migration, cycle and apoptosis were evaluated. Subsequently, the chemosensitivity of OC cells to cisplatin was verified. Finally, expression levels of let-7d-5p, HMGA1, p21, B-cell lymphoma-2 (Bcl-2)-associated X (Bax), p27, p53 wild-type (p53 $\left.3^{\mathrm{wt}}\right), \mathrm{p} 53$ mutated ( $\mathrm{p} 53^{\mathrm{mut}}$ ), proliferating cell nuclear antigen (PCNA), cyclin-dependent kinase 2 (CDK2), matrix metallopeptidase (MMP)2, MMP9 and Bcl-2 were determined As demonstrated in the results, let-7d-5p expression was low in OC tissues and had an increased reduction in the OVCAR-3 cell line. HMGA1 was confirmed as a target of let-7d-5p, and its expression was also silenced by let-7d-5p. let-7d-5p repressed OC cell viability, migration, cell cycle progression and apoptosis, while it promoted the chemosensitivity of OC cells
\end{abstract}

Correspondence to: Dr Yan Liu, Department of Obstetrics and Gynecology, The Third Affiliated Hospital of Zhengzhou University, 7 Front Kangfu Street, Zhengzhou, Henan 450052, P.R. China E-mail: drliu_ly@163.com

Key words: microRNA let-7d-5p, ovarian cancer, high mobility group A1, p53 signaling pathway, chemosensitivity, proliferation, apoptosis to cisplatin by targeting HMGA1. The expression of let-7d-5p, p21, Bax, p27 and p53 ${ }^{\mathrm{wt}}$ was increased, while that of HMGA1, p53 ${ }^{\text {mut }}$, PCNA, CDK2, MMP2, MMP9 and Bcl-2 was reduced following cell transfection. The results in the present study provided evidence that let-7d-5p may suppress proliferation, and facilitate apoptosis and cisplatin chemosensitivity of OC cells by silencing HMGA1 via the p53 signaling pathway.

\section{Introduction}

Ovarian cancer (OC) is the seventh most prevalent cancer types in females globally, accounting for $\sim 4 \%$ of all newly diagnosed female tumor cases $(1,2)$. It has been reported that OC is a type of highly metastatic gynecological malignancy, and the leading cause of gynecological cancer-associated mortalities globally with 140,000 mortalities and 225,000 new OC cases globally in $2008(3,4)$. The majority of OC cases are diagnosed in postmenopausal women globally (5). Treatment regimens include aggressive surgery and platinum/taxane chemotherapy (6). Surgery is beneficial not only in the diagnosis and staging of $\mathrm{OC}$ but also in the treatment of patients with highly metastatic and advanced OC (7). Although surgery and primary chemotherapy are effective for $\mathrm{OC}$ treatment, further novel therapies are also required to reduce the incidence of metastasis and recurrence (8). Based on the study by Jacobs et al (9), patients with OC exhibit an unfavorable prognosis, and the 5-year survival rate remains unsatisfactory globally. Recent studies have determined the crucial effect of microRNAs (miRs) on the development and prognosis of OC $(10,11)$. Therefore, it is necessary to investigate the effect of miRs on chemosensitivity, proliferation and apoptosis in OC.

miRs are short endogenous RNAs, 22 nucleotides in length, that regulate protein expression and control various biological behaviors, including cell development, carcinogenesis and other diverse cellular processes (12). It has been demonstrated that the miR let-7d, a tumor suppressor, exerts suppressive effect on epithelial-mesenchymal transition, migration and invasion of oral squamous cell carcinoma cells (13). Furthermore, let-7d is known as a therapeutic agent in triple-negative breast cancer by increasing the sensitivity of cancer cells to radiotherapy via targeting cancer stem cells and 
inhibiting the cyclin D1/Akt1/Wnt1 signaling pathway (14). Additionally, an upregulated let-7d-5p level has been reported to be associated with reduced peroxisome-proliferator activated receptor $\gamma$ expression (15). A recent report demonstrated that let-7d-3p acts as an oncogene in OC (16). let-7d serves a key role in altering the malignant cell phenotype of $\mathrm{OC}$ cells by mediating the expression of a number of molecules, including high mobility group A (HMGA) proteins (17). Bioinformatics analysis of the present study indicated HMGA1 as a target of let-7d-5p. HMGA1 is a small protein (10.6-12 kDa) acting as a disease biomarker and a potential cancer regulator (18). Furthermore, HMGA1 has been demonstrated to serve a vital role in drug resistance and self-renewal of OC stem cells (19). Additionally, HMGA1 regulates the p53 signaling pathway at the transcriptional level, thereby controlling the balance between symmetric and asymmetric divisions in cancer stem cells (20). HMGA1 is associated with p53, a major factor in insulin-like growth factor-1 receptor gene transcription, and has the ability to antagonize p53 activity (21). p53 is a sequence-specific DNA-binding protein and regulator at the transcriptional level, which is involved in the regulation of cellular activities under stress conditions (22). p53 is also one of the most crucial and frequently investigated tumor suppressors thus far, which affects diverse cellular processes, including cell death, senescence and cell cycle arrest (23). Evidence indicates that the control of intracellular localization of p53 is of notable importance in regulating cell apoptosis and chemosensitivity (24). Furthermore, Tenovin-1 is a type of agonist of the p53 signaling pathway that can increase the protein and mRNA levels of p53 and the p53 downstream target p21CIP/WAF1, while preventing degeneration of MDM2-mediated p53, thus avoiding possible side effects on the synthesis of p53 (25-27). In the present study, Tenovin-1 activated the $\mathrm{p} 53$ signaling pathway, verifying that let-7d-5p targeting HMGA1 was achieved through the p53 signaling pathway. Based on the aforementioned studies, a hypothesis was proposed that let-7d-5p could suppress OC development by regulating the p53 signaling pathway via HMGA1. Therefore, the present study investigated the underlying molecular mechanisms of let-7d-5p, HMGA1 and the p53 signaling pathway in chemosensitivity and apoptosis of OC cells, thus providing further effective therapy strategies for patients with OC.

\section{Materials and methods}

Ethics statement. The protocol was approved by the Ethics Committee of the Third Affiliated Hospital of Zhengzhou University (Zhengzhou, China). Written informed consent was obtained from the patients or patients' family.

Study subjects. A total of 76 female patients with OC (age range, 25-64 years; mean age, 45.26 \pm 12.04 years) were enrolled in The Third Affiliated Hospital of Zhengzhou University from January 2015 to January 2017. The 76 cases included 40 cases $\geq 44$ years and 36 cases $<44$ years. Of these, 47 cases were diagnosed as serous carcinoma, 11 cases as endometrioid carcinoma, 6 cases as clear cell carcinoma, 6 cases as mixed carcinoma and 6 cases as mucinous carcinoma. All these patients had received prior surgical treatment. Neoplastic foci central tissues and adjacent normal tissues were confirmed by pathological examination and had not undergone chemotherapy, radiotherapy or immunotherapy during previous surgeries. The pathologists were blinded to the study. Tissue samples were excised, resected and immediately stored in liquid nitrogen at $-196^{\circ} \mathrm{C}$.

Construction of plasmids. The let-7d-5p mimic plasmid was constructed by Sangon Biotech Co., Ltd. (Shanghai, China) using the hsa-let-7d-5p sequence obtained from the miRBase database (http://www.mirbase.org) 5'-AGAGGUAGUAGGU UGCAUAGUU-3'. The cleavage sites of endonuclease EcoRI and BamHI were inserted into both ends of the hsa-let-7d-5p sequence, and the synthesized two pairs of single-stranded DNA oligo were subjected to annealing to form double-stranded DNA oligo. The obtained annealing product was identified by 4\% agarose gel electrophoresis. Following this, the DNA products were purified according to the instructions of DNA gel extraction kit (DP1601; Bioteke Corporation, Beijing, China). The products $(3.5 \mu \mathrm{l})$ were mixed with linear pcDNA TM6.2GW/Em GFP miR vector $(1 \mu \mathrm{l})$ (Invitrogen; Thermo Fisher Scientific, Inc., Waltham, MA, USA), T4 DNA Ligase $(1 \mu \mathrm{l})$ and $2 \mathrm{X}$ Lig Buffer $(5 \mu \mathrm{l})$ for $12 \mathrm{~h}$ at $16^{\circ} \mathrm{C}$. Subsequently, the products were transformed into DH5 $\alpha$ competent cells, with $10 \mu \mathrm{l}$ products being transformed into $100 \mu \mathrm{l}$ products. The connected products were transferred into an EP tube supplemented with DH5 $\alpha$ competent cells, mixed, placed on ice for $30 \mathrm{~min}$, heat-shock for $90 \mathrm{sec}$ at $42^{\circ} \mathrm{C}$ and finally on ice for $5 \mathrm{~min}$. Afterwards, $900 \mu \mathrm{l}$ Luria-Bertani culture medium (10 $\mathrm{g}$ tryptone, $5 \mathrm{~g}$ yeast extract and $5 \mathrm{~g} \mathrm{NaCl}$; $\mathrm{pH}$ was adjusted to 7.4; the volume was adjusted to 11 by deionized water and autoclaved) was added into the EP tube followed by centrifugation at $6 \mathrm{xg}$ for $1.5 \mathrm{~h}$ at $37^{\circ} \mathrm{C}$, and at $2,500 \mathrm{xg}$ for $5 \mathrm{~min}$ at room temperature. Subsequently, the supernatant was discarded with only 100-200 $\mu$ l left. After being mixed, 100-200 $\mu 1$ supernatant was spread over the surface of a Luria-Bertani plate. The positive clones of spectinomycin were screened and amplified. Subsequently, the plasmids were extracted by double enzyme digestion using EcoRI $(1 \mu \mathrm{l})$ and BamHI (1 $\mu \mathrm{l})$ endonuclease (Promega Corporation, Madison, WI, USA), $\mathrm{ddH}_{2} \mathrm{O}(11 \mu \mathrm{l}), 10 \mathrm{X}$ Tango $(2 \mu \mathrm{l})$, and plasmid $(1 \mu \mathrm{l})$ for $4 \mathrm{~h}$ at $37^{\circ} \mathrm{C}$. The small interfering (si)-HMGA1 plasmid was designed and constructed by Thermo Fisher Scientific, Inc. using RNAi software (Qiagen GmbH, Hilden, Germany) on the basis of the HMGA1 siRNA sequence in the HMGA1 gene bank (https://www.ncbi.nlm.nih.gov/) (sense strand, 5'-UGGAGAAGGAGGAAGAGGAdTdTAGCTT-3'; and antisense strand, 3'-CCTAGdTdTACCUCUUCCUCCUUCU CCU-5'). Both ends of siRNA sequence included the cleavage sites of EcoRI and BamHI. The synthetic complementary strand of HMGA1 siRNA was subjected to annealing at $70^{\circ} \mathrm{C}$ for $30 \mathrm{sec}$. Furthermore, T4 DNA ligase (Invitrogen; Thermo Fisher Scientific, Inc.) was adopted to connect the cleavage sites between EcoRI and BamHI in the pSilence4.1-CMV-neo carrier (Invitrogen; Thermo Fisher Scientific, Inc.). The plasmid was transformed into DH5 $\alpha$ competent cells (JZ003; Fenghui Biotech Co., Ltd., Changsha, China), and then the positive cell clones were selected, amplified and added into Luria-Bertani culture medium at $37^{\circ} \mathrm{C}$ for $18 \mathrm{~h}$. Plasmid extraction was conducted by double enzyme digestion using 
EcoRI and BamHI endonuclease (Promega Corporation) at $37^{\circ} \mathrm{C}$ for $4 \mathrm{~h}$ to verify.

Bioinformatics prediction and dual-luciferase reporter gene assay. The online bioinformatics website (microRNA.org) was used to predict whether HMGA1 is the target gene of let-7d-5p. The HMGA1-wild-type (WT) was designed on the basis of binding sequence, and mutant sites of the noncomplementary strand of the seed sequence were designed in HMGA1-WT, named HMGA1-mutant (MUT). HMGA1-MUT and HMGA1-WT were inserted into the pMIR-reporter vector using T4 DNA ligase following cleavage by restriction endonuclease. Recombinant WT and MUT reporter plasmids were co-transfected into HEK-293T cells (Shanghai Xin Yu Biotech Co. Ltd, Shanghai, China) with the let-7d-5p mimic or negative control (NC) plasmids ( $2 \mu \mathrm{g}$; Invitrogen; Thermo Fisher Scientific, Inc.). The cells were added with $200 \mu 1$ serum-free Opti-MEM containing $6 \mu$ l Lipofectamine ${ }^{\circledR} 2000$ (11668-019; Invitrogen; Thermo Fisher Scientific, Inc.) and incubated at room temperature for $20 \mathrm{~min}$, followed by addition of M199 medium (SH30025.01B; Hyclone; GE Healthcare Life Sciences, Logan, UT, USA) containing 10\% fetal bovine serum (FBS; 10099141; Gibco; Thermo Fisher Scientific, Inc.). Cells were allocated into group I [co-transfected with NC plasmid and HMGA1-WT 3'-untranslated region (UTR)], group II (co-transfected with let-7d-5p mimic plasmid and HMGA1-WT 3'-UTR), group III (co-transfected with NC plasmid and HMGA1-MUT 3'-UTR) and group IV (co-transfected with let-7d-5p mimic plasmid and HMGA1-MUT 3'-UTR). After 48 h of transfection, cells were collected, lysed with radioimmunoprecipitation assay (RIPA) cell lysis buffer (R0010; Beijing Solarbio Science \& Technology Co., Ltd., Beijing, China) and centrifuged $\left(4^{\circ} \mathrm{C}\right)$ at $28,985 \mathrm{x}$ g for 3-5 min, and then the supernatant was obtained. Subsequently, the Renilla luciferase assay buffer and the firefly luciferase assay agent were dissolved according to the luciferase assay kit (RG005; Beyotime Institute of Biotechnology, Shanghai, China). Buffer solution of the kit $(100 \mu \mathrm{l})$ was obtained for each sample. Renilla luciferase assay working solution was prepared with the addition of substrate (1:100), which was detected using fluorimetry. A $20 \mu \mathrm{l}$ sample was extracted from each group for detection. Subsequently, $100 \mu$ l firefly luciferase assay agent was added, and a pipette was used to triturate. The cell lysate of the reporter gene was used as the blank control. Subsequently, luciferase assay working fluid of the kit $(100 \mu \mathrm{l})$ was added. A Dual-luciferase reporter assay kit (RG008; Beyotime Institute of Biotechnology) and a microplate reader (Multiskan MK3; Thermo Fisher Scientific, Inc.) were used to assess the relative luciferase unit (RLU) at $560 \mathrm{~nm}$ following trituration using a pipette. Renilla luciferase was used as the internal reference, and luciferase activity was obtained through the ratio of the RLU value of firefly luciferase to the RLU value of Renilla luciferase.

Cell selection and grouping. OC cell lines (SKOV3, A2780, OVCAR-3 and CaOV3; Cell Center of Chinese Academy of Medical Sciences, Beijing, China). and human normal ovarian epithelial cell line IOSE-80 (American Type Culture Collection, Manassas, VA, USA) were cultured in M199 cell culture medium and incubated at $37^{\circ} \mathrm{C}$ in an atmosphere containing $5 \% \mathrm{CO}_{2}$. The cell culture medium was changed every
2 days, and cells were digested and passaged at a ratio of 1:3 approximately 3 days later. Reverse transcription-quantitative polymerase chain reaction (RT-qPCR) was performed to detect the expression of let-7d-5p in different OC cell lines and ovarian epithelial cell lines, according to the subsequent protocols, and the OC cell line with the lowest expression was selected for the following experiment. Cells were divided into the control group (without any treatment), let-7d-5p mimic group (transfected with let-7d-5p mimic plasmid), NC group (transfected with NC plasmid), siHMGA1 group (transfected with siHMGA1 plasmid), Tenovin-1 group (treated with Tenovin-1; 3365-10; Shanghai Haoran Biotechnology Co., Ltd, Shanghai, China), let-7d-5p inhibitor group (transfected with let-7d-5p inhibitor plasmid), let-7d-5p inhibitor + siHMGA1 group (transfected with let-7d-5p inhibitor and siHMGA1 plasmids) and let-7d-5p mimic + siHMGA1 + Tenovin-1 group (transfected with let-7d-5p mimic, siHMGA1 and Tenovin-1 plasmids). When cells (OVCAR-3 and A2780) were in the logarithmic growth phase, they were detached with $0.25 \%$ trypsin. Subsequently, cells were resuspended at $11 \times 10^{5}$ cells/ml with M199 culture medium containing $10 \% \mathrm{FBS}$, inoculated in a 6 -well plate at $37^{\circ} \mathrm{C}$. When cells grew to $70 \%$ confluence, they were cultured in a newly replaced serum-free M199 medium for $24 \mathrm{~h}$ and then transfected with different plasmids according to grouping. A total of $200 \mu \mathrm{l}$ serum-free Opti-MEM medium (31985070; Gibco; Thermo Fisher Scientific, Inc.) was used to dilute $6 \mu 1$ Lipofectamine ${ }^{\circledR} 2000$ (11668-019; Invitrogen; Thermo Fisher Scientific, Inc.), which was thoroughly mixed. Subsequently, $100 \mu 1$ serum-free Opti-MEM medium from the let-7d-5p mimic group, the siHMGA1 group and the NC group was used to dilute $2 \mu \mathrm{g}$ let-7d-5p mimic or pSilencer4 1-CMV-Hs plasmids, which were thoroughly mixed. The two mixed solutions aforementioned were rested at room temperature for $10 \mathrm{~min}$, and then they were completely mixed and incubated at room temperature for $20 \mathrm{~min}$, named transfection complex. The former culture medium in the 6-well plate was discarded, and $180 \mu \mathrm{l}$ fresh Opti-MEM medium was added to each well. Transfection complex was also added into the cell wells. Subsequently, dimethyl sulfoxide-diluted Tenovin-1 (Tnv-1; Cayman Chemical Company, Ann Arbor, MI, USA) was added to the Tenovin-1 and let-7d-5p mimic + siHMGA1 + Tenovin-1 groups (final concentration, $10 \mu \mathrm{M})$. When performing TdT-mediated dUTP-biotin nick end-labeling (TUNEL) staining, according to the subsequent protocol, $\alpha$-tocopheryl succinate (Sigma-Aldrich; Merck KGaA, Darmstadt, Germany) dissolved in $4 \%$ ethanol was added with the final concentration of $0.2 \%(\mathrm{v} / \mathrm{v})$ in the culture medium as a positive control group. Culture medium was replaced with fresh medium following cells being cultured at $37^{\circ} \mathrm{C}$ in an atmosphere containing $5 \% \mathrm{CO}_{2}$ for $18 \mathrm{~h}$. Cells were harvested after $48 \mathrm{~h}$ of transfection.

MTT assay. The MTT (Clontech Laboratories, Inc., Mountainview, CA, USA) colorimetric assay was adopted to detect cell viability. OVCAR-3 and A2780 cells in the logarithmic growth phase were collected from each group following transfection and cell suspensions were produced $\left(3 \times 10^{4}\right.$ cells $\left./ \mathrm{ml}\right)$ in M199 culture medium containing $10 \%$ FBS. The cell suspension was inoculated in a 96-well plate, with $200 \mu \mathrm{l} /$ well $\left(6 \times 10^{3}\right.$ cells/well). Cells were further 
cultured in an incubator at $37^{\circ} \mathrm{C}$ for $24 \mathrm{~h}$, and the former medium was removed $2 \mathrm{~h}$ after cells were adherent to the well. Subsequently, $5 \mathrm{mg} / \mu \mathrm{l}$ MTT solution was added into each well (20 $\mu \mathrm{l} /$ well), and cells were further incubated at $37^{\circ} \mathrm{C}$ for $4 \mathrm{~h}$. After the medium in each well was removed, $150 \mu 1$ 10\% SDS was added. The optical density value of each well was detected using an enzyme-linked immunosorbent assay plate reader (Shanghai Precision Instrument Co., Ltd., Shanghai, China) at a wavelength of $490 \mathrm{~nm}$. Cells were counted once a day after the 1st day of incubation for a consecutive 6 days.

Transwell assay. OVCAR-3 and A2780 cells in the logarithmic growth phase were collected from each group following transfection, and then resuspended using Dulbecco's modified Eagle's medium (DMEM; Gibco; Thermo Fisher Scientific, Inc.) to a density of $2 \times 10^{5}$ cells $/ \mathrm{ml}$. The cell suspension $(200 \mu \mathrm{l})$ was added into the apical chamber, and DMEM containing 10\% FBS $(600 \mu \mathrm{l})$ was placed into the basolateral chamber. OVCAR-3 and A2780 were collected after 24 h of culture, and cotton swabs were used to wipe off cells on the surface of the apical chamber. A total of 5 fields were randomly selected from each membrane following 4\% formaldehyde fixation at room temperature for $1 \mathrm{~h}$ and crystal violet staining at room temperature for $30 \mathrm{~min}$. The number of cells in each visual field was calculated under the inverted fluorescence microscope at x400 magnification (DMi8; Leica Microsystems GmbH, Wetzlar, Germany), and the mean value was obtained. A total of 3 duplicated wells were set up for each group, and the migration capacity of OC cells was represented by the number of migrating cells.

Flow cytometry. After transfection for 48 h, OVCAR-3 and A2780 cells were collected, washed with cold PBS 3 times and centrifuged at $450 \mathrm{x}$ g for $5 \mathrm{~min}$ at room temperature, followed by removal of the supernatant. Cells were then resuspended with PBS for cell counting and adjusted to a density of $1 \times 10^{6}$ cells $/ \mathrm{ml}$. Cells were fixed with $75 \%$ ethanol precooled to $-20^{\circ} \mathrm{C}$ for $1 \mathrm{~h}$ at $4^{\circ} \mathrm{C}$ and centrifuged $\left(4^{\circ} \mathrm{C}\right)$ at $450 \mathrm{xg}$ for $5 \mathrm{~min}$, after which the ethanol was removed. The supernatant was discarded following the cells being washed with PBS twice. Subsequently, $100 \mu 1$ cell suspension with a density of $1 \times 10^{6}$ cells/ml was collected and added to $100 \mu \mathrm{l}$ RNase A, avoiding light, and then treated in a $37^{\circ} \mathrm{C}$ water bath in the dark for $30 \mathrm{~min}$, followed by staining with $400 \mu \mathrm{l}$ propidium iodide (D0820; Sigma-Aldrich; Merck $\mathrm{KGaA}$ ) at $40^{\circ} \mathrm{C}$ for $30 \mathrm{~min}$ without light exposure. Cell cycle was evaluated through the detection of red fluorescence using a flow cytometer (Cytomics FC 500; Beckman Coulter, Inc., Brea, CA, USA) at an excitation wavelength of $488 \mathrm{~nm}$. The fluorescent probe kit Pe-cy5 (7850-250; Biovision Inc., Milpitas, CA, USA) was used, and FlowJo 7.6.5 software (FlowJo LLC, Ashland, OR, USA) was applied for analysis.

TUNEL staining. Following transfection for $48 \mathrm{~h}, \mathrm{OVCAR}-3$ and A 2780 cells were collected, adjusted to a density of $5 \times 10^{7}$ cells $/ \mathrm{ml}$ using PBS, and fixed with $4 \%$ neutral formaldehyde at room temperature for $10 \mathrm{~min}$. The cell suspension $(50 \mu \mathrm{l})$ was dropped onto glass slides, dried and washed with PBS twice (5 min each). PBS containing $2 \%$ hydrogen peroxide was added to the staining jar of slides, with which cells reacted at room temperature for 5 min, followed by two PBS washes (5 min each). Excess liquid was removed using filter paper, and 2 drops of TdT staining buffer (3.63 g Trlzma base was adjusted to $\mathrm{pH} 7.2$ with $0.1 \mathrm{~N}$ $\mathrm{HCl}$, and $\mathrm{ddH}_{2} \mathrm{O}$ was added to adjust to a volume of 1,000 1, and then $29.96 \mathrm{~g}$ sodium dimethylsulphate and $0.238 \mathrm{~g}$ cobalt chloride were added) were added to the slides, which were allowed to rest at room temperature for 1-5 min. After excess liquid was removed using filter paper again, cells were treated with $\mathrm{TdT}$ reactive liquid $(54 \mu \mathrm{l})$ in a humidity chamber at $37^{\circ} \mathrm{C}$ for $1 \mathrm{~h}$. TdT reactive liquid was prepared with $32 \mu \mathrm{l}$ TdT enzyme (KGF012; KeyGen Biotech Co., Ltd., Nanjing, China) and $76 \mu \mathrm{l}$ TdT staining buffer. The NC staining was set as reactive liquid without TdT staining buffer. Glass slides were then placed in staining jars and washed at $37^{\circ} \mathrm{C}$ in buffer solution (17.4 $\mathrm{g} \mathrm{NaCl}, 8.82 \mathrm{~g}$ sodium citrate and 1,000 $\mathrm{ml} \mathrm{ddH}_{2} \mathrm{O}$ ) to terminate the reaction, which was then allowed to rest at $37^{\circ} \mathrm{C}$ for $30 \mathrm{~min}$. Glass slides were lifted and placed once every 10 min and washed with PBS three times ( 5 min each). The sections were then incubated with 2 drops of peroxide-labeled digoxin antibody (cat. no. B7952; 1:500; Shanghai Point Optical Instrument Co., Ltd., Shanghai, China) in a humidity chamber at room temperature for $30 \mathrm{~min}$, followed by 4 PBS washes $(5 \mathrm{~min}$ each). Staining was performed with $0.05 \%$ diaminobenzidine (DAB) liquid at room temperature for 3-6 min. Subsequently, the sections were washed with distilled water 4 times ( 1 min for the first three and $5 \mathrm{~min}$ for the last), and were counterstained with $0.5 \%$ methyl green at room temperature for $10 \mathrm{~min}$. The sections were lifted and placed 10 times during the first 2 distilled water washes, and then they were rested for $30 \mathrm{sec}$ in the last distilled water wash. The identical method was used for 3 washes with $100 \%$ butanol as well as 3 dehydrations with xylene ( 2 min each). Subsequently, the sections were mounted and dried. A brown-colored nucleus indicated positive apoptotic cells, with sections without TdT used as a NC. Cells were counted under an optical microscope at x400 magnification, with five visual fields randomly selected for each slide. Cell apoptosis was observed under an optical microscope (Shanghai Point Optical Instrument Co., Ltd.). The apoptosis rate of cells was obtained in five high-power fields. Apoptosis rate $(\%)=($ the number of apoptotic cells/the number of total cells) x $100 \%$.

Colony formation assay. OVCAR-3 and A2780 cells in the logarithmic growth phase were collected and detached with trypsin to produce cell suspensions. Cells were then stained with $0.4 \%$ trypan blue at room temperature for $5 \mathrm{~min}$, counted and adjusted to a density of 500 cells/ml using M199 culture medium containing 10\% FBS. Culture medium $(1 \mathrm{ml})$ and diluted cell suspension $(1 \mathrm{ml})$ were added into a 6-well plate and mixed with $0.5,1.0$ and $3.0 \mu \mathrm{g} / \mathrm{ml}$ cisplatin (Shanghai Hengyuan Biological Technology Co., Ltd., Shanghai, China). A total of 3 wells were set up for each group. Cells were cultured at $37^{\circ} \mathrm{C}$ in an atmosphere containing $5 \% \mathrm{CO}_{2}$ for 1 week and stained with $10 \%$ Giemsa (Shanghai Haling Biotechnology Co., Ltd., Shanghai, China) at room temperature for $15 \mathrm{~min}$. The number of colonies with $>50$ cells was calculated under an inverted fluorescence microscope at x400 magnification.

$R T$-qPCR. A TRIzol ${ }^{\circledR}$ kit (Shanghai Haling Biotechnology Co., Ltd.) was used to extract RNA from OC tissues and adjacent normal tissues, as well as the total RNA of transfected cells (OVCAR-3 and A2780), after $24 \mathrm{~h}$ of incubation at $37^{\circ} \mathrm{C}$. Nano-Drop (ND-1000) spectrophotometry and $1 \%$ agarose 
Table I. The primer sequences for reverse transcription-quantitative polymerase chain reaction.

\begin{tabular}{ll} 
Gene & \multicolumn{1}{c}{ Primer sequence (5'-3') } \\
\hline U6 & F: CTCGCTTCGGCAGCACA \\
& R: AACGCTTCACGAATTTGCGT \\
GAPDH & F: GGAGCGAGATCCCTCCAAAAT \\
& R GGCTGTTGTCATACTTCTCATGG \\
let-7d-5p & F: GGCATGGACGAGCTGTACAA \\
& R: CTCTAGATCAACCACTTTGT \\
HMGA1 & F: GCTGGTAGGGAGTCAGAAGGA \\
& R: TGGTGGTTTCCGGGTCTTG \\
P53 & F: CAGCACATGACGGAGGTTGT \\
& R: TCATCCAAATACTCCACACGC
\end{tabular}

HMGA1, high mobility group A1; F, forward; R, reverse; wt, wild-type.

gel electrophoresis were used to measure RNA concentration, integrity and purity. According to the protocols of the TransScript Reverse Transcriptase kit (AT-101; Beijing TransGen Biotech Co., Ltd., Beijing, China), reverse transcription was conducted in a PCR amplification instrument to synthesize cDNA templates. The designed let-7d-5p, HMGA1, p53 wild-type (p53 $3^{\mathrm{wt}}$ ), U6 and GAPDH were all synthesized by Beijing Genomics Institute Co., Ltd. (Shenzhen, Guangdong, China; Table I). The reaction system $(20 \mu \mathrm{l})$ for reverse transcription was prepared according to the protocols for EasyScript First-Strand cDNA Synthesis Supermix (AE301-02; Beijing TransGen Biotech Co., Ltd.). RT-qPCR was performed according to the protocols for SYBR $^{\circledR}$ Premix Ex Taq ${ }^{\mathrm{TM}}$ II kit (Takara Biotechnology Co., Ltd., Dalian, China). The PCR reaction system $(20 \mu \mathrm{l})$ was SYBR Premix $(10 \mu \mathrm{l})$, cDNA template $(2 \mu \mathrm{l})$, forward primer $(0.6 \mu \mathrm{l})$, reverse primer $(0.6 \mu \mathrm{l})$ and sterile water $(6.8 \mu \mathrm{l})$. The RT-qPCR assay was conducted in an ABI-7500 real-time PCR instrument (ABI Research, Oyster Bay, NY, USA). U6 was considered the internal control for let-7d-5p expression, whereas GAPDH was used as the internal control for other target genes. Reaction conditions were as follows: pre-denaturation at $95^{\circ} \mathrm{C}$ for $30 \mathrm{sec}$, denaturation at $95^{\circ} \mathrm{C}$ for $30 \mathrm{sec}$, annealing at $60^{\circ} \mathrm{C}$ for $20 \mathrm{sec}$ and extension at $72^{\circ} \mathrm{C}$ for $30 \mathrm{sec}$, with a total of 45 cycles. The expression of let-7d and HMGA1 was then measured. The $2^{-\Delta \Delta \mathrm{Cq}}$ method (28) was used for quantitative analysis. $2^{-\Delta \Delta C q}$ represented the proportion of gene expression between the experimental group and control group. The formula was $\Delta \Delta \mathrm{Cq}=\Delta \mathrm{Cq}_{\text {experimental group }}-\Delta \mathrm{Cq}_{\text {control group }} \mathrm{Cq}$ indicated the number of amplification cycles when the real-time fluorescence intensity reached the quantification value. Furthermore, amplification was in the logarithmic growth phase.

Western blot analysis. A total of $100 \mu 1$ RIPA cell lysis buffer (P0013B; Beyotime Institute of Biotechnology) was dissolved and mixed with the $1 \mu 1$ phenylmethylsulfonyl fluoride (PMSF) (ST506; Beyotime Institute of Biotechnology) lysis buffer, and the PMSF concentration was adjusted to $1 \mathrm{mM}$. Followed by centrifugation at $450 \mathrm{xg}$ for $5 \mathrm{~min}$ at room temperature, OVCAR-3 cells were collected at room temperature, washed once with PBS and resuspended in $5 \mathrm{ml} \mathrm{M} 199$ medium containing $10 \%$ FBS. Subsequently, centrifugation at $450 \mathrm{x} \mathrm{g}$ for $5 \mathrm{~min}$ at room temperature was performed again and the deposit was obtained. The RIPA cell lysis buffer was added into the deposit at a ratio of $100 \mu \mathrm{l}$ buffer $/ 1 \times 10^{7}$ cells. Following slight shaking and resuspension in RIPA cell lysis buffer, cells were cooled in an ice bath at $4^{\circ} \mathrm{C}$ for $5 \mathrm{~min}$, and centrifuged $\left(4^{\circ} \mathrm{C}\right)$ for $10 \mathrm{~min}$ at $25,764 \mathrm{x}$ g. The supernatant was collected as the total protein, and the protein concentration of each sample was determined using a bicinchoninic acid kit (20201ES76; Shanghai Yeasen Biotech Co., Ltd., Shanghai, China). Total protein (30 $\mu \mathrm{g})$ was subjected to $10 \%$ SDS-PAGE and transferred onto a polyvinylidene fluoride membrane in electroporation with a constant flow 200A for $2 \mathrm{~h}$ by using the wet electrophoretic transfer method. The membrane was blocked with 5\% skim milk powder at room temperature for $2.5 \mathrm{~h}$ and then washed with $1 \mathrm{X}$ Tris-buffered saline with $0.001 \%$ Tween-20 (TBST) 3 times (5 min each). Subsequently, the membrane was incubated at $4^{\circ} \mathrm{C}$ overnight with the following primary antibodies: Rabbit anti-human HMGA1 (ab129153; 1:10,000 dilution); rabbit anti-human p53 mutated (p53 ${ }^{\text {mut }}$ (ab32049; 1:1,000 dilution); mouse anti-human p53 ${ }^{\mathrm{wt}}$ (ab26; 1:10,000 dilution); rabbit anti-human p21 (ab109520; 1:10,000 dilution); rabbit anti-human B-cell lymphoma-2 (Bcl-2)-associated X (Bax; ab32503; 1:10,000 dilution); rabbit anti-human Bcl-2 (ab182858; 1:2,000 dilution); rabbit anti-human p27 (aba32034; 1:10,000 dilution); mouse anti-human proliferating cell nuclear antigen (PCNA; ab29; 1:1,000); rabbit anti-human cyclin-dependent kinase 2 (CDK2; ab32147; 1:10,000 dilution); rabbit anti-human matrix metalloproteinase 2 (MMP2; ab37150; 1:1,000); rabbit anti-human MMP9 (ab38898; 1:10,000 dilution); and mouse anti-human GAPDH (ab8245; 1:10,000 dilution) (all from Abcam, Cambridge, MA, USA). Subsequently, the membrane was washed with 1X TBST 3 times (5 min each). Secondary antibodies, including goat anti-rabbit IgG H\&L (horseradish peroxidase-conjugated; ab6721; 1:2,000 dilution; Abcam) and goat anti-mouse IgG H\&L (fluorescein isothiocyanate-conjugated; ab6785; 1:10,000 dilution; Abcam) were added, after which the membrane was incubated at room temperature for $1 \mathrm{~h}$ and then washed with 1X TBST 3 times. Images were acquired by sensitized electroluminescence (TANON-5500; Tanon Science and Technology Co., Ltd., Shanghai, China). The gray value of target protein bands was quantified using ImageJ software 1.44d (National Institutes of Health, Bethesda, MD, USA).

Statistical analysis. Data were analyzed by SPSS 21.0 software (IBM Corp. Armonk, NY, USA), and the data are presented with mean \pm standard deviation. All experiments were conducted at least three times. Differences between two groups were analyzed by paired Student's t-test, while differences between multiple groups were analyzed by one-way analysis of variance followed by a Tukey's post hoc test. $\mathrm{P}<0.05$ was considered to indicate a statistically significant difference.

\section{Results}

let-7d-5p is poorly expressed in OC tissues. RT-qPCR was performed to detect let-7d-5p levels in OC and adjacent normal 


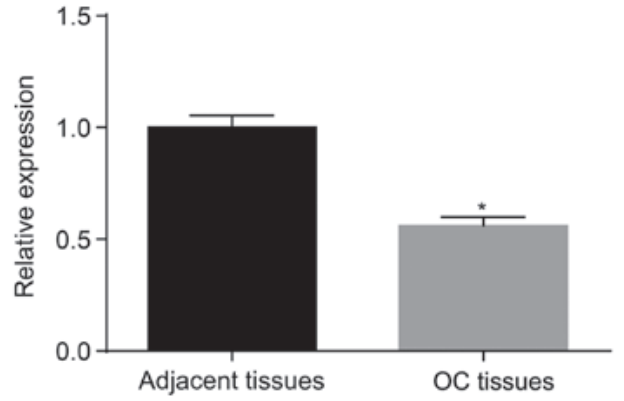

Figure 1. let-7d-5p exhibits low expression in OC tissues ( $\mathrm{n}=76) .{ }^{*} \mathrm{P}<0.05$, compared with adjacent normal tissues. Measurement data are presented as the mean \pm standard deviation. Comparison between the two groups was conducted using a paired Student's t-test. OC, ovarian cancer.

tissues. The results (Fig. 1) demonstrated that the expression of let-7d-5p in OC tissues was significantly reduced, compared with the adjacent normal tissues $(\mathrm{P}<0.05)$. Thus, it can be inferred that expression of let-7d-5p was low in OC tissues.

let-7d-5p has reduced expression in cell lines OVCAR-3 and A2780. Subsequently, RT-qPCR was utilized to determine let-7d-5p expression in OC cell lines SKOV3, A2780, OVCAR-3 and $\mathrm{CaOV} 3$, and human normal ovarian epithelial cell line IOSE-80 (Fig. 2). The results demonstrated that compared with normal ovarian epithelial cell line IOSE-80, let-7d-5p expression was significantly reduced in OC cell lines SKOV3, A2780, OVCAR-3 and CaOV3 (all P<0.05). let-7d-5p exhibited the lowest expression in OVCAR-3 and A2780 cells, which were selected for the following experiment.

HMGA1 is a target gene of let-7d-5p. To search for the target gene of let-7d-5p, the bioinformatics website microRNA.org and a dual luciferase reporter gene assay were utilized to predict and verify the target association between let-7d-5p and HMGA1. As depicted in Fig. 3A, microRNA.org demonstrated that let-7d-5p targeted the sequence of 3'-UTR in HMGA1. The dual-luciferase reporter gene assay (Fig. 3B) demonstrated that the luciferase activity of let-7d-5p and HMGA1-WT co-transfected group was significantly decreased, compared with the $\mathrm{NC}$ group $(\mathrm{P}<0.05)$. However, no significant difference was observed in the luciferase activity of HMGA1-MUT and the NC group $(\mathrm{P}>0.05)$. Thus, it was concluded that let- $7 \mathrm{~d}-5 \mathrm{p}$ targeted HMGA1.

let-7d-5p represses OVCAR-3 and A2780 cell viability by targeting HMGA1. An MTT colorimetric assay was performed to detect cell viability (Fig. 4). Compared with the control group, OVCAR-3 and A2780 cell viability did not significantly differ among all groups on day $1(\mathrm{P}>0.05)$. Additionally, on days $2-6$, there was no significant difference in cell viability between the NC and let-7d-5p inhibitor + siHMGA1 groups $(\mathrm{P}>0.05)$. Furthermore, the let-7d-5p inhibitor group exhibited significantly elevated cell viability $(\mathrm{P}<0.01)$, whereas significantly decreased cell viability was observed in the let-7d-5p mimic, siHMGA1 and Tenovin-1 groups $(\mathrm{P}<0.05)$, and there was a substantially increased reduction in the let-7d-5p mimic + siHMGA1 + Tenovin-1 group $(\mathrm{P}<0.01)$. Compared with the let-7d-5p mimic group on days

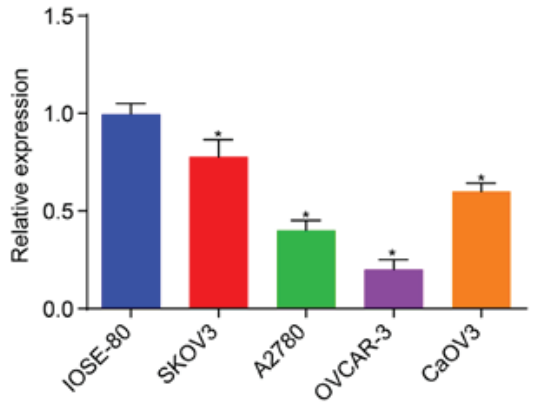

Figure 2. let-7d-5p exhibits the lowest expression in the ovarian cancer cell lines OVCAR-3 and A2780. U6 was used as an internal control. ${ }^{*} \mathrm{P}<0.05$, compared with ovarian epithelial cell line IOSE-80. Measurement data are presented as the mean \pm standard deviation. Comparison among multiple groups was conducted using analysis of variance. The experiment was repeated 3 times.

$2-6$, the cell viability was significantly decreased in the let-7d-5p mimic + siHMGA1 + Tenovin-1 group $(\mathrm{P}<0.05)$. In comparison with the let-7d-5p inhibitor group, the let-7d-5p inhibitor + siHMGA1 group exhibited significantly reduced cell viability $(\mathrm{P}<0.05)$. Thus, these data revealed that let-7d-5p and siHMGA1 inhibited OVCAR-3 and A2780 cell viability.

let-7d-5p and silencing of HMGA1 suppress OVCAR-3 and A2780 cell migration. A Transwell assay was performed to detect OVCAR-3 and A2780 cell migration ability following transfection in each group. The results (Fig. 5) demonstrated that compared with the control group, the cell migration ability did not differ significantly in the NC and let-7d-5p inhibitor+siHMGA1 groups $(\mathrm{P}>0.05)$. Additionally, the let-7d-5p inhibitor group exhibited significantly elevated cell migration ability $(\mathrm{P}<0.05)$, and the cell migration ability was significantly downregulated in the let-7d-5p mimic, siHMGA1 and Tenovin-1 groups $(\mathrm{P}<0.05)$, and there was increased significant reduction in the let-7d-5p mimic + siHMGA1 + Tenovin-1 group $(\mathrm{P}<0.01)$. Compared with the let-7d-5p mimic group, cell migration exhibited a significantly reduced level in the let-7d-5p mimic + siHMGA1 + Tenovin-1 group $(\mathrm{P}<0.05)$. In contrast with the let-7d-5p inhibitor group, the let-7d-5p inhibitor + siHMGA1 group exhibited a significantly decreased cell migration ability $(\mathrm{P}<0.05)$. Thus, it was concluded that siHMGA1 and let-7d-5p reduced OVCAR-3 and A2780 cell migration.

let-7d-5d and HMGA1 silencing inhibit cell cycle progression in OVCAR-3 and A2780 cells. The OVCAR-3 and A2780 cell cycle following transfection was detected by flow cytometry (Fig. 6). Compared with the control group, there were no significant differences in cells arrested in the $S, G_{2} / M$ and $\mathrm{G}_{1} / \mathrm{G}_{0}$ phases in the NC and let-7d-5p inhibitor + siHMGA1 groups $(\mathrm{P}>0.05)$. Additionally, the $\mathrm{S}$ phase fraction was significantly increased, while the $\mathrm{G}_{1} / \mathrm{G}_{0}$ phase fraction was significantly reduced in the let-7d-5p inhibitor group $(\mathrm{P}<0.05)$. Furthermore, the let-7d-5p mimic, siHMGA1 and Tenovin-1 groups exhibited significantly decreased cells arrested in the $\mathrm{S}$ phase and significantly increased cells arrested in the $\mathrm{G}_{1} / \mathrm{G}_{0}$ phase $(\mathrm{P}<0.05)$. The identical trend was observed in the let-7d-5p mimic + siHMGA1 + Tenovin-1 group; however, 


\section{A hsa-let-7d/HMGA1 Alignment

\begin{tabular}{|c|c|c|c|c|c|}
\hline 3 & 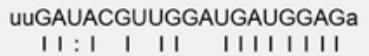 & $5^{\prime}$ & hsa-let-7d & mirSVR score: & -0.9303 \\
\hline $166: 5^{\prime}$ & CUCUGUUC - ACAAACUACCUAU & 3 & HMGA1 & PhastCons score: & 0.6580 \\
\hline
\end{tabular}

B

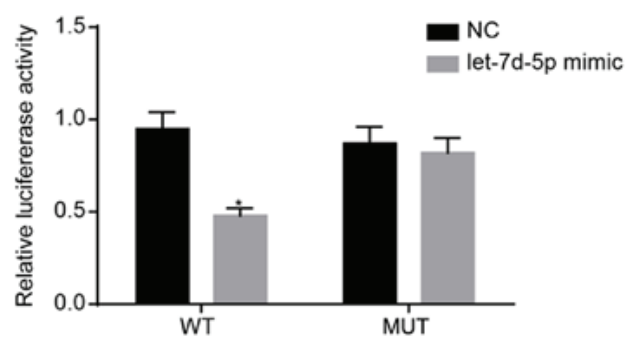

Figure 3. let-7d-5p targets HMGA1. (A) Binding sequence between let-7d-5p and 3'-untranslated region of HMGA1 predicted by bioinformatics website microRNA.org. (B) Statistics of relative luciferase activity in the NC and let-7d-5p mimic groups verified with a dual-luciferase reporter assay. " $\mathrm{P}<0.05$, compared with the NC group. Measurement data are presented as the mean \pm standard deviation. Comparison between the NC group and the let-7d-5p mimic groups was conducted using independent sample Student's t-test. The experiment was repeated 3 times. HMGA1, high mobility group A1; NC, negative control; WT, wild-type HMGA1; MUT, mutant HMGA1.

A

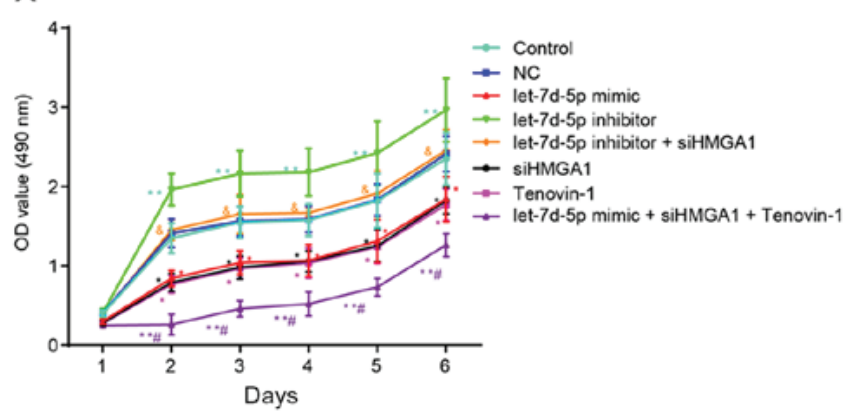

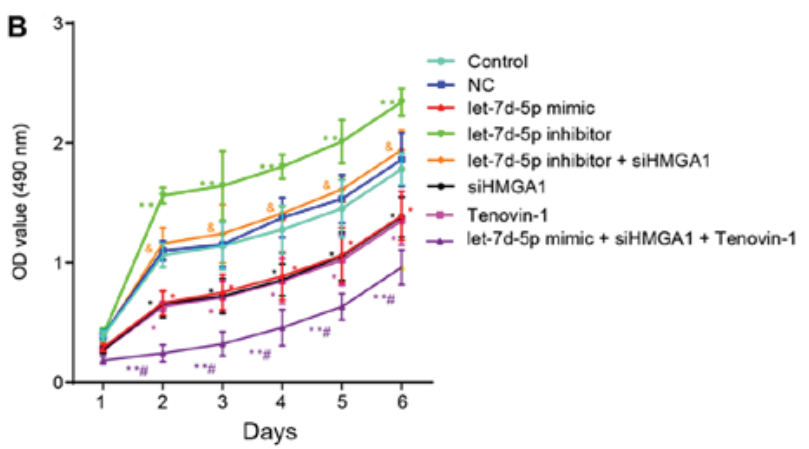

Figure 4. let-7d-5p and silencing of HMGA1 inhibit ovarian cancer cell viability. (A) OVCAR-3 cell viability in each group detected with an MTT assay. (B) A2780 cell viability in each group detected with an MTT assay. ${ }^{*} \mathrm{P}<0.05$, compared with the control group at the identical time point; *" $\mathrm{P}<0.01$, compared with the control group at the identical time point; ${ }^{\&} \mathrm{P}<0.05$, compared with the let-7d-5p inhibitor group at the identical time point; ${ }^{\prime} \mathrm{P}<0.05$, compared with the let-7d-5p mimic group at the identical time point. Measurement data are presented as the mean \pm standard deviation. Comparison among multiple groups was conducted using analysis of variance. The experiment was repeated 3 times. HMGA1, high mobility group A1; NC, negative control; si, small interfering; OD, optical density.
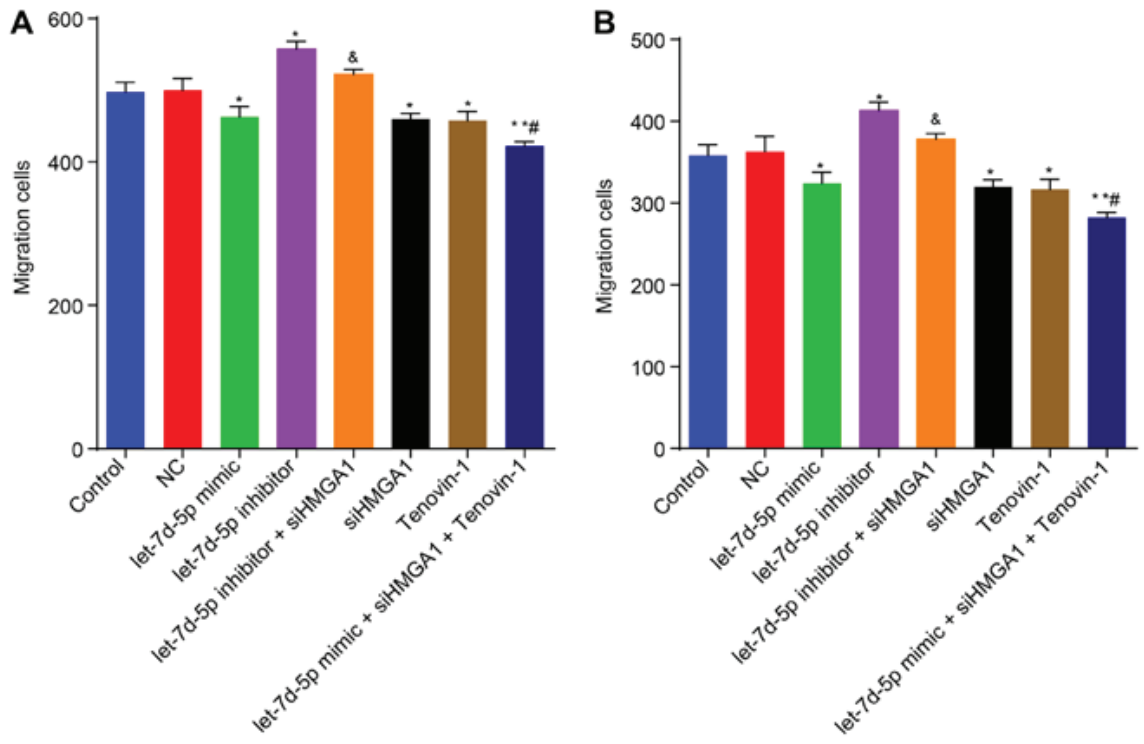

Figure 5. let-7d-5p and silenced HMGA1 suppress ovarian cancer cell migration. (A) OVCAR-3 cell migration ability in each group detected with a Transwell assay. (B) A2780 cell migration ability in each group detected with a Transwell assay. ${ }^{*} \mathrm{P}<0.05$, compared with the control group; ${ }^{* *} \mathrm{P}<0.01$, compared with the control group; ${ }^{\&} \mathrm{P}<0.05$, compared with the let-7d-5p inhibitor group; ${ }^{*} \mathrm{P}<0.05$, compared with the let-7d-5p mimic group. Measurement data are presented as the mean \pm standard deviation. Comparison among multiple groups was conducted using analysis of variance. The experiment was repeated 3 times. HMGA1, high mobility group A1; NC, negative control; si, small interfering. 

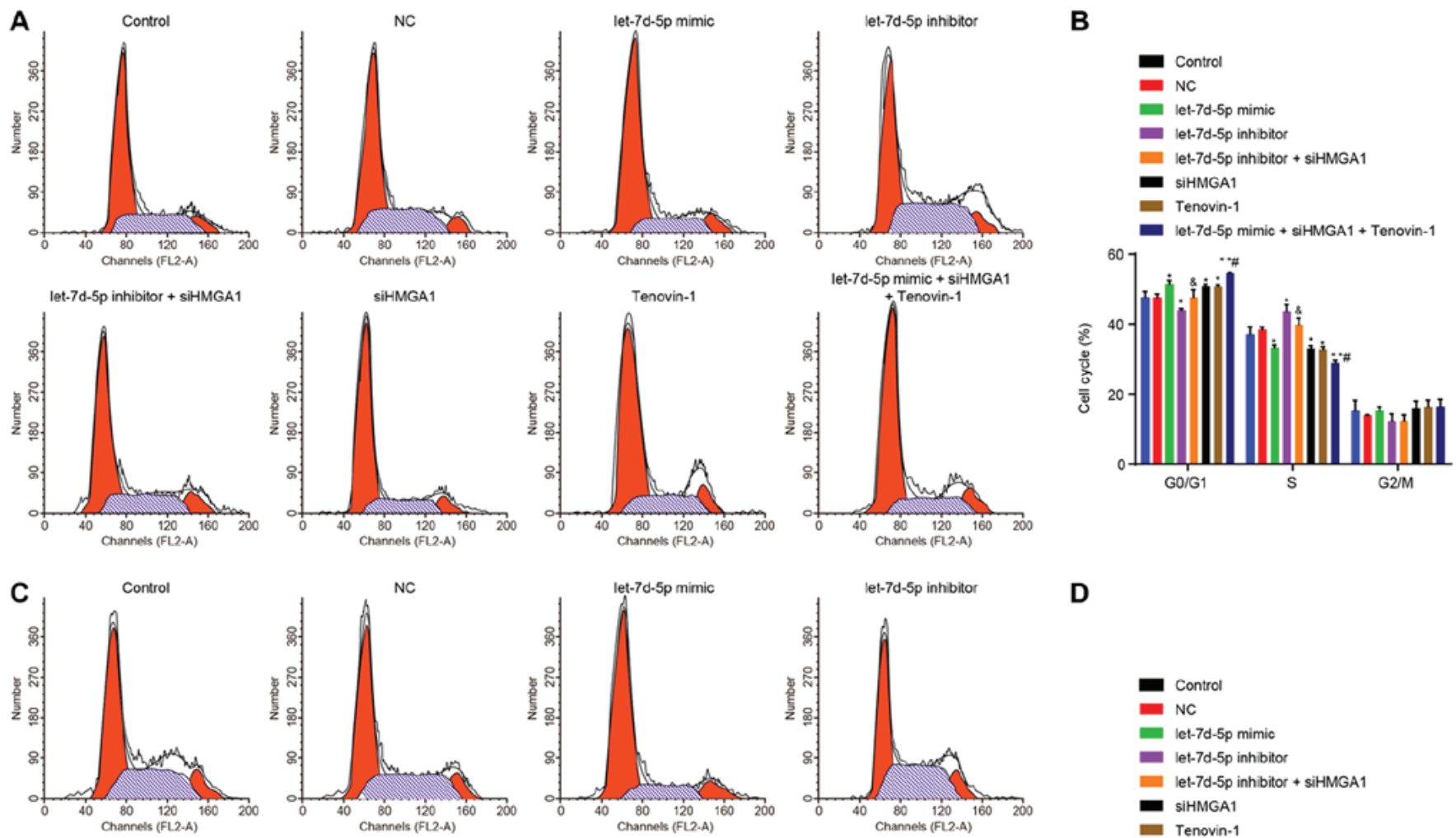

D
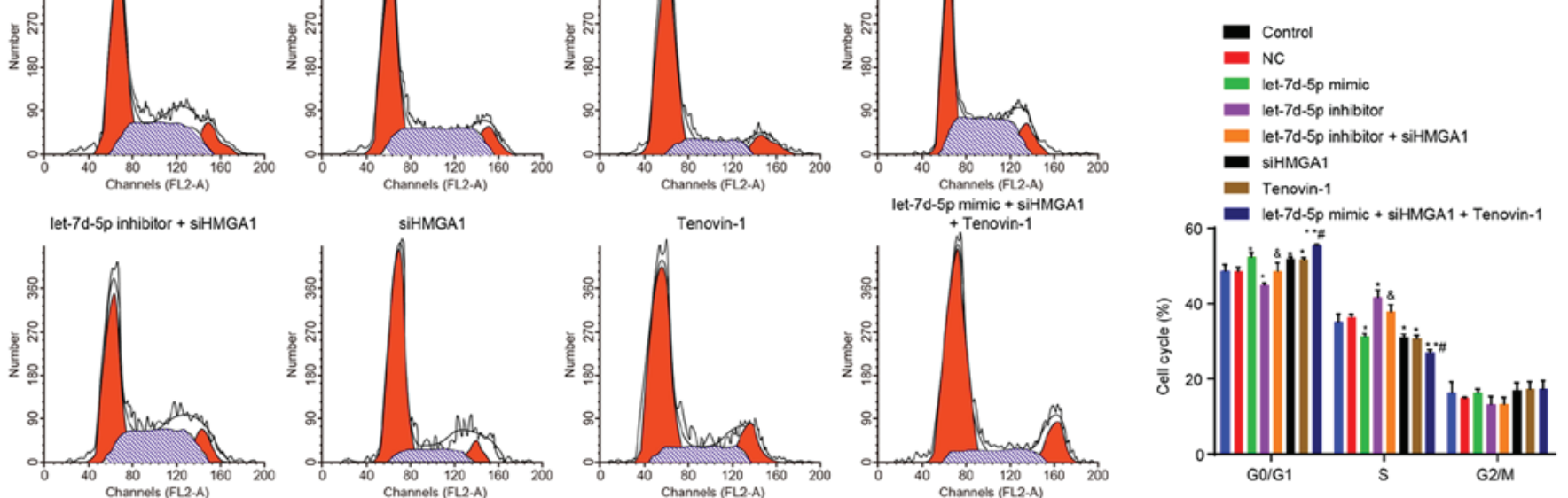

Figure 6. let-7d-5d and HMGA1 silencing restrain cell cycle progression in ovarian cancer cells. (A) OVCAR-3 cell cycle images in each group. (B) The cell proportion of OVCAR-3 cell cycle in each phase. (C) A2780 cell cycle images in each group. (D) The cell proportion of A2780 cell cycle in each phase. "P<0.05, compared with the control group; ${ }^{* *} \mathrm{P}<0.01$, compared with the control group; ${ }^{\&} \mathrm{P}<0.05$, compared with the let-7d-5p inhibitor group; ${ }^{*} \mathrm{P}<0.05$, compared with the let-7d-5p mimic group. Measurement data are presented as the mean \pm standard deviation. Comparison among multiple groups was conducted using analysis of variance. The experiment was repeated 3 times. HMGA1, high mobility group A1; si, small interfering; NC, negative control.

the difference had increased significance $(\mathrm{P}<0.01)$. Compared with the let-7d-5p mimic group, the $\mathrm{S}$ phase was significantly reduced, and the $\mathrm{G}_{1} / \mathrm{G}_{0}$ phase was significantly increased in the let-7d-5p mimic + siHMGA1 + Tenovin-1 group $(\mathrm{P}<0.05)$. In comparison with the let-7d-5p inhibitor group, the let-7d-5p inhibitor + siHMGA1 group exhibited significantly reduced cells arrested in the $S$ phase and significantly increased cells arrested in the $\mathrm{G}_{1} / \mathrm{G}_{0}$ phase $(\mathrm{P}<0.05)$. Thus, the aforementioned results revealed that let-7d-5d and HMGA1 silencing decreased cell cycle progression in OVCAR-3 and A2780 cells.

let-7d-5d and silencing HMGAl enhance OVCAR-3 and A2780 cell apoptosis. TUNEL staining was employed to identify OVCAR-3 and A2780 cell apoptosis following transfection in each group. As depicted in Fig. 7, cell contraction, karyopyknosis and brown-colored staining were observed in parts of the OVCAR-3 and A2780 cells under optical microscopy. Cells with such features were considered apoptotic cells, while normal cell nuclei were presented with blue staining. Compared with the control group, the apoptosis rate in the NC and let-7d-5p inhibitor + siHMGA1 groups did not differ significantly $(\mathrm{P}>0.05)$. Additionally, the let-7d-5p inhibitor group exhibited a significantly decreased cell apoptosis rate $(\mathrm{P}<0.05)$; however, the apoptosis rate was significantly increased in the let-7d-5p mimic, siHMGA1 and Tenovin-1 groups $(\mathrm{P}<0.05)$ and had a greater significant increase in the let-7d-5p mimic + siHMGA1 + Tenovin-1 and positive control groups $(\mathrm{P}<0.01)$. Compared with the let-7d-5p mimic group, cell apoptosis rates exhibited a significant increase in the let-7d-5p mimic + siHMGA1 + Tenovin-1 and positive control groups $(\mathrm{P}<0.05)$. Compared with the let-7d-5p inhibitor group, the let-7d-5p inhibitor + siHMGA1 group exhibited a significantly increased cell apoptosis rate $(\mathrm{P}<0.05)$. Therefore, it could be inferred that let-7d-5d and silencing HMGA1 promoted OVCAR-3 and A2780 cell apoptosis.

let-7d-5d enhances chemosensitivity of OVCAR-3 and A2780 cells to cisplatin by targeting HMGA1. A colony formation assay was used to measure chemosensitivity of OVCAR-3 


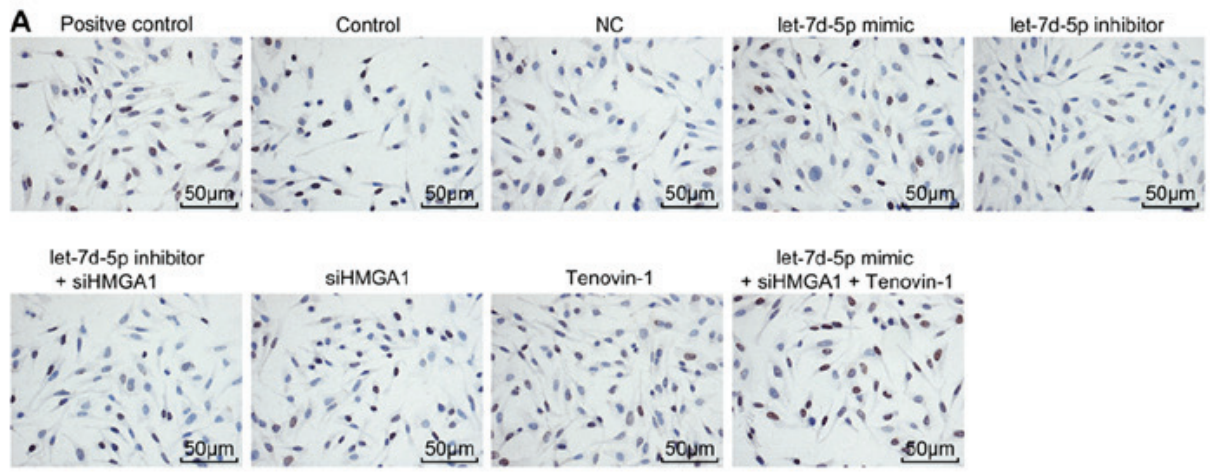

C Positve control

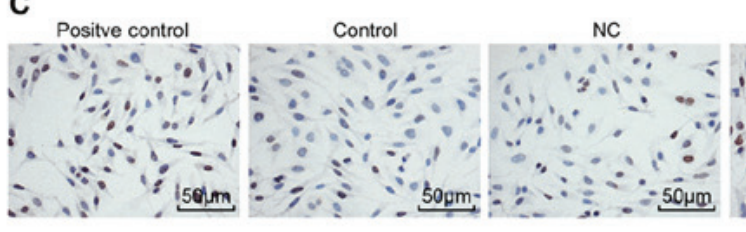

let-7d-5p mimic
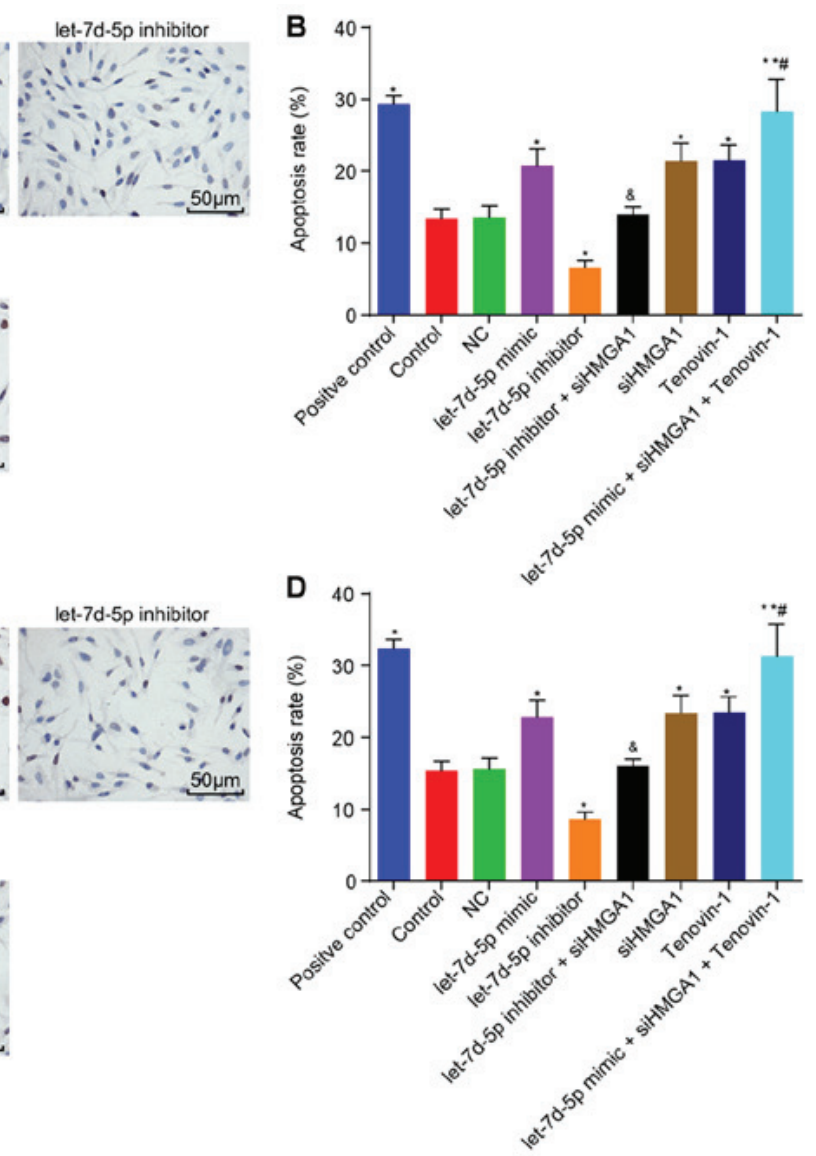

Figure 7. let-7d-5d and silenced HMGA1 inhibit ovarian cancer cell apoptosis. (A) Staining images for apoptosis of OVCAR-3 cells observed under optical microscopy, Scale bar=50 $\mu \mathrm{m}$. (B) Apoptosis rate (\%) of OVCAR-3 cells in each group. (C) Staining images for apoptosis of A2780 cells observed under optical microscopy, Scale bar $=50 \mu \mathrm{m}$. (D) Apoptosis rate (\%) of A2780 cells in each group. ${ }^{*} \mathrm{P}<0.05$, compared with the control group; ${ }^{* * *} \mathrm{P}<0.01$, compared with the control group; ${ }^{\&} \mathrm{P}<0.05$, compared with the let-7d-5p inhibitor group; ${ }^{*} \mathrm{P}<0.05$, compared with the let-7d-5p mimic group. Measurement data are presented as the mean \pm standard deviation. Comparison among multiple groups was conducted using analysis of variance. The experiment was repeated 3 times. HMGA1, high mobility group A1; NC, negative control; si, small interfering.

and A2780 cells to cisplatin following transfection in each group. As depicted in Tables II and III, the chemosensitivity of OVCAR-3 and A2780 cells to different concentrations of cisplatin was represented by the number of colonies formed, with reduced colonies reflecting increased chemosensitivity. Cisplatin was selected with a volume of $0.5-1 \mu \mathrm{g} / \mathrm{ml}$. The results demonstrated that compared with the control group, the number of colonies formed was significantly increased in the let-7d-5p inhibitor group $(\mathrm{P}<0.05)$, while no significant difference was determined in the $\mathrm{NC}$ and let-7d-5p inhibitor + siHMGA1 groups ( $\mathrm{P}>0.05)$; however, colony numbers were significantly reduced in the let-7d-5p mimic, siHMGA1 and Tenovin-1 groups $(\mathrm{P}<0.05)$ and had an increased significant reduction in the let-7d-5p mimic + siHMGA1 + Tenovin-1 group $(\mathrm{P}<0.01)$. Compared with the let-7d-5p mimic group, the let-7d-5p mimic + siHMGA1 + Tenovin-1 group exhibited significantly decreased colony formation $(\mathrm{P}<0.05)$. Compared with the let-7d-5p inhibitor group, the let-7d-5p inhibitor + siHMGA1 group exhibited significantly decreased colony formation $(\mathrm{P}<0.05)$. In comparison with the control group, the number of colonies formed did not differ significantly in the $\mathrm{NC}$ group when cisplatin was $3 \mu \mathrm{g} / \mathrm{ml}(\mathrm{P}>0.05)$, while it was significantly downregulated (the number of colonies formed $=0$ ) in the let-7d-5p, siHMGA1, Tenovin-1 and let-7d-5p mimic + siHMGA $1+$ Tenovin-1 groups $(\mathrm{P}<0.05)$. Thus, these results revealed that let-7d-5d increased chemosensitivity of OVCAR-3 and A2780 cells to cisplatin by targeting HMGA1.

The expression levels of let-7d-5p and $p 53^{w t}$ are increased while mRNA expression of HMGAl is reduced following transfection with let-7d-5p mimic and siHMGA1. RT-qPCR was used to determine mRNA expression of associated factors (Fig. 8). Compared with the control group, let-7d-5p expression did not differ significantly in the NC, siHMGA1 and Tenovin-1 groups $(\mathrm{P}>0.05)$, but it was significantly elevated in the let-7d-5p mimic and let-7d-5p mimic + siHMGA1 + Tenovin-1 groups $(\mathrm{P}<0.05)$. Additionally, the let-7d-5p inhibitor + siHMGA1 and let-7d-5p inhibitor groups exhibited significant reductions in let-7d-5p expression $(\mathrm{P}<0.05)$. In comparison with the control group, mRNA expression of HMGA1 did not differ significantly in the NC, Tenovin-1 and let-7d-5p inhibitor + siHMGA1 groups $(\mathrm{P}>0.05)$. Additionally, it was significantly reduced in the let-7d-5p mimic and siHMGA1 groups and had an increased significantly reduction in the let-7d-5p mimic + siHMGA1 + Tenovin-1 group $(\mathrm{P}<0.01)$, whereas the let-7d-5p inhibitor group demonstrated a significantly increased mRNA expression of HMGA1 $(\mathrm{P}<0.05)$. In contrast with the control group, the mRNA expression of $\mathrm{p} 53^{\mathrm{wt}}$ did not differ 
Table II. The colony formation number of OVCAR-3 cells with different concentrations $(0.5,1$ and $3 \mu 1)$ of cisplatin in each group.

Colony formation number with various cisplatin concentrations $(\mu \mathrm{g} / \mathrm{ml})$

\begin{tabular}{lccc} 
Groups & 0.5 & 1.0 & 3.0 \\
\cline { 2 - 4 } Control group & $60.33 \pm 4.16$ & $31.33 \pm 3.21$ & $10.00 \pm 1.00$ \\
NC group & $63.67 \pm 4.62$ & $33.00 \pm 1.73$ & $8.33 \pm 1.15$ \\
let-7d-5p mimic group & $50.33 \pm 2.31^{\mathrm{a}}$ & $7.00 \pm 1.00^{\mathrm{a}}$ & $0.00^{\mathrm{a}}$ \\
let-7d-5p inhibitor group & $75.67 \pm 4.73^{\mathrm{a}}$ & $40.00 \pm 2.00^{\mathrm{a}}$ & $15.00 \pm 1.00^{\mathrm{a}}$ \\
let-7d-5p inhibitor + siHMGA1 group & $64.67 \pm 4.16^{\mathrm{c}}$ & $35.00 \pm 2.00 \mathrm{c}$ & $9.00 \pm 1.00$ \\
siHMGA1 group & $50.00 \pm 1.00^{\mathrm{a}}$ & $8.33 \pm 0.58^{\mathrm{a}}$ & $0.00^{\mathrm{a}}$ \\
Tenovin-1 group & $49.33 \pm 2.52^{\mathrm{a}}$ & $8.67 \pm 0.58^{\mathrm{a}}$ & $0.00^{\mathrm{a}}$ \\
let-7d-5p mimic + siHMGA1 + Tenovin-1 group & $39.33 \pm 0.58^{\mathrm{b}, \mathrm{d}}$ & $0.00^{\mathrm{b}, \mathrm{d}}$ &
\end{tabular}

${ }^{\mathrm{a}} \mathrm{P}<0.05$, compared with the control group; ${ }^{\mathrm{b}} \mathrm{P}<0.01$, compared with the control group; ${ }^{\mathrm{c}} \mathrm{P}<0.05$, compared with the let- $7 \mathrm{~d}-5 \mathrm{p}$ inhibitor group; ${ }^{\mathrm{d}} \mathrm{P}<0.05$, compared with the let-7d-5p mimic group; Measurement data are presented as the mean \pm standard deviation. Comparison among multiple groups is analyzed using analysis of variance. The experiment was repeated 3 times. HMGA1, high mobility group A1; NC, negative control; si, small interfering.

Table III. The colony formation number of A2780 cells with different concentrations of cisplatin $(0.5,1$ and $3 \mu 1)$ in each group. Colony formation number with various cisplatin concentrations $(\mu \mathrm{g} / \mathrm{ml})$

\begin{tabular}{|c|c|c|c|}
\hline Groups & 0.5 & 1.0 & 3.0 \\
\hline Control group & $55.67 \pm 4.04$ & $29.00 \pm 1.73$ & $9.00 \pm 1.00$ \\
\hline NC group & $58.67 \pm 4.73$ & $26.67 \pm 3.06$ & $7.33 \pm 1.53$ \\
\hline let-7d-5p mimic group & $45.33 \pm 2.31^{\mathrm{a}}$ & $5.67 \pm 0.58^{\mathrm{a}}$ & $0.00^{\mathrm{a}}$ \\
\hline let-7d-5p inhibitor group & $70.67 \pm 4.93^{\mathrm{a}}$ & $40.00 \pm 1.73^{\mathrm{a}}$ & $13.00 \pm 1.00^{\mathrm{a}}$ \\
\hline let-7d-5p inhibitor + siHMGA1 group & $60.00 \pm 4.58^{\mathrm{c}}$ & $28.00 \pm 1.73^{\mathrm{c}}$ & $7.00 \pm 1.00$ \\
\hline siHMGA1 group & $45.00 \pm 1.00^{\mathrm{a}}$ & $6.33 \pm 0.58^{\mathrm{a}}$ & $0.00^{\mathrm{a}}$ \\
\hline Tenovin-1 group & $44.00 \pm 2.65^{\mathrm{a}}$ & $6.67 \pm 0.58^{a}$ & $0.00^{\mathrm{a}}$ \\
\hline let-7d-5p mimic + siHMGA1 + Tenovin-1 group & $33.33 \pm 0.58^{\mathrm{b}, \mathrm{d}}$ & $0.00^{\mathrm{b}, \mathrm{d}}$ & $0.00^{\mathrm{a}}$ \\
\hline
\end{tabular}

${ }^{\mathrm{a}} \mathrm{P}<0.05$, compared with the control group; ${ }^{\mathrm{b}} \mathrm{P}<0.01$, compared with the control group; ${ }^{\mathrm{c}} \mathrm{P}<0.05$, compared with the let-7d-5p inhibitor group. ${ }^{\mathrm{d}} \mathrm{P}<0.05$, compared with the let- $7 \mathrm{~d}-5 \mathrm{p}$ mimic group; Measurement data are presented as mean \pm standard deviation. Comparison among multiple groups is analyzed using analysis of variance. The experiment was repeated 3 times. HMGA1, high mobility group A1; NC, negative control; si, small interfering.

significantly in the NC and let-7d-5p inhibitor + siHMGA1 groups $(\mathrm{P}>0.05)$. Additionally, it was significantly increased in the let-7d-5p mimic, siHMGA1 and Tenovin-1 groups $(\mathrm{P}<0.05)$, and had a greater significant increase in the let-7d-5p mimic + siHMGA1 + Tenovin-1 group $(\mathrm{P}<0.01)$; however, the let-7d-5p inhibitor group exhibited significantly reduced mRNA expression of $\mathrm{p} 53^{\mathrm{wt}}(\mathrm{P}<0.05)$. In the let-7d-5p mimic + siHMGA1 + Tenovin-1 group, the mRNA expression of HMGA1 was at a significantly reduced level and the mRNA expression of $\mathrm{p} 53^{\mathrm{wt}}$ was at a significantly increased level, compared with the let-7d-5p mimic group $(\mathrm{P}<0.05)$. Compared with the let-7d-5p inhibitor group, the let-7d-5p inhibitor + siHMGA1 group exhibited significantly reduced mRNA expression of HMGA1 and significantly increased the mRNA expression of $\mathrm{p} 53^{\mathrm{wt}}(\mathrm{P}<0.05)$. Thus, the aforementioned demonstrated that cells transfected with let-7d-5p mimic and siHMGA1 exhibited an increased expression of let-7d-5p and $\mathrm{p} 53^{\mathrm{wt}}$ and a reduced mRNA expression of HMGA1.

Protein expression of p21, Bax, p27 and p53 ${ }^{w t}$ is increased while that of p53 ${ }^{\text {mut }}$, PCNA, CDK2, MMP2, MMP9, Bcl-2 and HMGAl is reduced following transfection with let-7d-5p mimic and siHMGA1. Western blot analysis was employed to determine the protein expression of associated factors (Fig. 9). The results demonstrated that compared with the control group, the protein expression of p21, Bax, p27 and p53 ${ }^{\mathrm{wt}}$ did not differ significantly in the $\mathrm{NC}$ and let-7d-5p inhibitor + siHMGA1 groups $(\mathrm{P}>0.05)$. Additionally, they were significantly increased in the let-7d-5p mimic, siHMGA1 and Tenovin-1 groups $(\mathrm{P}<0.05)$, 

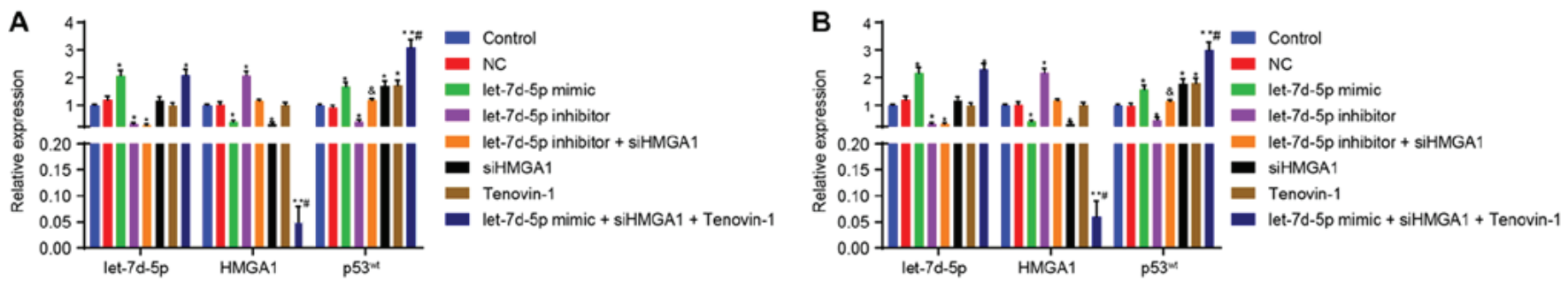

Figure 8. Expression of let-7d-5p and mRNA expression of $\mathrm{p} 53^{\mathrm{wt}}$ are increased while mRNA expression of HMGA1 is decreased following ovarian cancer cells being transfected with let-7d-5p and siHMGA1. (A) Relative expression of let-7d-5p, HMGA1 and p53 ${ }^{\mathrm{wt}}$ in OVCAR-3 cells detected by RT-qPCR. (B) Relative expression of let-7d-5p, HMGA1 and p53 ${ }^{\mathrm{wt}}$ in A2780 cells detected by RT-qPCR. U6 was used as the internal control of let-7d-5p, while GAPDH was used as the internal control of HMGA1 and $\mathrm{p} 53^{\mathrm{wt}}$. Expression of associated genes in each group in contrast with the control group. "P $<0.05$, compared with the control group; ${ }^{* *} \mathrm{P}<0.01$, compared with the control group; ${ }^{\circledR} \mathrm{P}<0.05$, compared with the let- $7 \mathrm{~d}-5 \mathrm{p}$ inhibitor group; ${ }^{*} \mathrm{P}<0.05$, compared with the let-7d-5p mimic group. Measurement data are presented as the mean \pm standard deviation. Comparison among multiple groups was conducted using analysis of variance. The experiment was repeated 3 times. HMGA1, high mobility group A1; RT-qPCR, reverse transcription quantitative polymerase chain reaction; NC, negative control; si, small interfering.
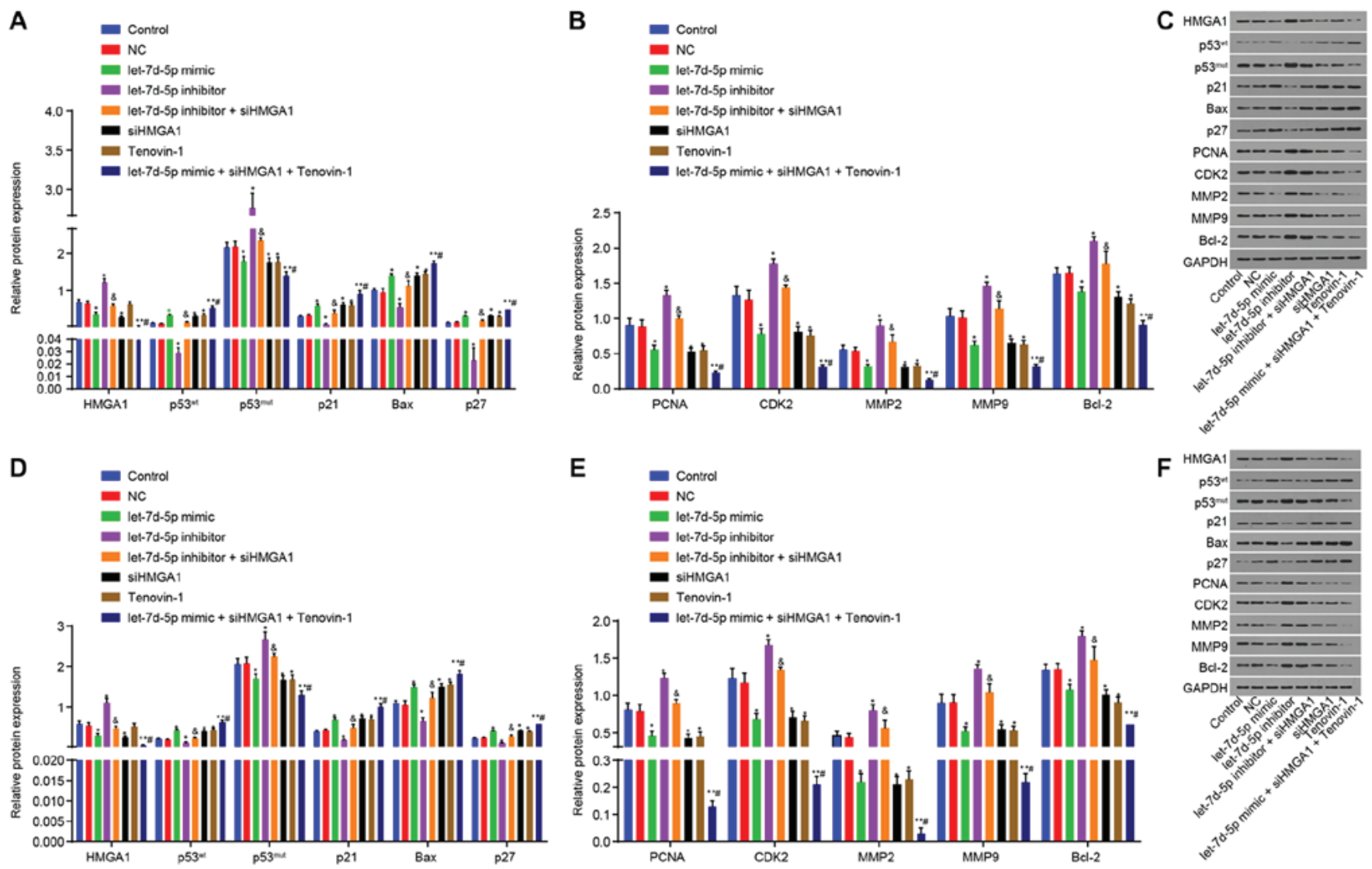

Figure 9. Protein expression of p21, Bax, p27 and p53 ${ }^{\mathrm{wt}}$ is increased, while that of p53 ${ }^{\mathrm{mut}}$, PCNA, CDK2, MMP2, MMP9, Bcl-2 and HMGA1 is reduced following ovarian cancer cells being transfected with let-7d-5p and siHMGA1. (A) Relative protein expression of HMGA1, p53 $3^{\mathrm{wt}}$, p53 ${ }^{\mathrm{mut}}$, p21, Bax and p27 in OVCAR-3 cells detected by western blot analysis. (B) Relative protein expression of PCNA, CDK2, MMP2, MMP9 and Bcl-2 in OVCAR-3 cells detected by western blot analysis. (C) Western protein bands of HMGA1, p53 $3^{\mathrm{wt}}$, p53 $3^{\mathrm{mut}}$, p21, Bax, p27, PCNA, CDK2, MMP2, MMP9, Bcl-2 and GAPDH detected in OCVAR-3 cells in each group. (D) Relative protein expression of HMGA1, p53 ${ }^{\mathrm{wt}}$, p53 ${ }^{\mathrm{mut}}$, p21, Bax and p27 in A2780 cells detected by western blot analysis. (E) Relative protein expression of PCNA, CDK2, MMP2, MMP9 and Bcl-2 in A2780 cells detected by western blot analysis. (F) Western protein bands of HMGA1, p53 ${ }^{\mathrm{wt}}$, p53 ${ }^{\mathrm{mut}}$, p21, Bax, p27, PCNA, CDK2, MMP2, MMP9, Bcl-2 and GAPDH detected in A2780 cells in each group. Gray value analysis was conducted using ImageJ software. ${ }^{*} \mathrm{P}<0.05$, compared with the control group; ${ }^{* *} \mathrm{P}<0.01$, compared with the control group; ${ }^{\&} \mathrm{P}<0.05$, compared with the let-7d-5p inhibitor group; ${ }^{*} \mathrm{P}<0.05$, compared with the let-7d-5p mimic group. Measurement data are presented as the mean \pm standard deviation. Comparison among multiple groups was conducted using analysis of variance. The experiment was repeated 3 times. HMGA1, high mobility group A1 protein; PCNA, proliferating cell nuclear antigen; Bcl-2, B-cell lymphoma-2; Bax, Bcl-2-associated X; CDK2, cyclin-dependent kinase 2; MMP, matrix metalloproteinases; $\mathrm{NC}$, negative control; si, small interfering.

and the increase had greater significance in the let-7d-5p mimic + siHMGA1 + Tenovin-1 group $(\mathrm{P}<0.01)$; however, the let-7d-5p inhibitor group exhibited significantly reduced protein expression of p21, Bax, p27 and p53 ${ }^{\mathrm{w}}(\mathrm{P}<0.05)$. Compared with the let-7d-5p mimic group, the protein expression of $\mathrm{p} 21, \mathrm{Bax}, \mathrm{p} 27$ and $\mathrm{p} 53^{\mathrm{wt}}$ was significantly 
elevated in the let-7d-5p mimic + siHMGA $1+$ Tenovin- 1 group $(\mathrm{P}<0.05)$. Compared with the let-7d-5p inhibitor group, the let-7d-5p inhibitor + siHMGA1 group exhibited significantly increased protein expression of $\mathrm{p} 21, \mathrm{Bax}, \mathrm{p} 27$ and $\mathrm{p} 53^{\mathrm{wt}}(\mathrm{P}<0.05)$.

Compared with the control group, no significant differences in the protein expression of $\mathrm{p} 53^{\mathrm{mut}}$, PCNA, CDK2, MMP2, MMP9 and Bcl-2 were observed in the NC and let-7d-5p inhibitor+siHMGA1 groups $(\mathrm{P}>0.05)$, whereas thesefactors were significantly downregulated in the let-7d-5p mimic, siHMGA1 and Tenovin-1 groups $(\mathrm{P}<0.05)$, and had an increased significant decrease in the let-7d-5p mimic + siHMGA1 + Tenovin-1 group $(\mathrm{P}<0.01)$; however, the let-7d-5p inhibitor group exhibited significantly elevated protein expression of $\mathrm{p} 53^{\mathrm{mut}}$, PCNA, CDK2, MMP2, MMP9 and Bcl-2 $(\mathrm{P}<0.05)$. In comparison with the let-7d-5p mimic group, the protein expression of $\mathrm{p} 53^{\mathrm{mut}}$, PCNA, CDK2, MMP2, MMP9 and Bcl-2 was significantly decreased in the let-7d-5p mimic + siHMGA1 + Tenovin-1 group $(\mathrm{P}<0.05)$. Compared with the let-7d-5p inhibitor group, the let-7d-5p inhibitor + siHMGA1 group had significantly reduced protein expression of $\mathrm{p} 53^{\mathrm{mut}}$, PCNA, CDK2, MMP2, MMP9 and Bcl-2 $(\mathrm{P}<0.05)$.

Compared with the control group, HMGA1 protein expression did not differ significantly in the NC, Tenovin-1 and let-7d-5p inhibitor + siHMGA1 groups $(\mathrm{P}>0.05)$, while it was significantly reduced in the let-7d-5p mimic and siHMGA1 groups $(\mathrm{P}<0.05)$, and the decrease had greater significance in the let-7d-5p mimic + siHMGA1 + Tenovin-1 group $(\mathrm{P}<0.01)$; however, the let-7d-5p inhibitor group exhibited significantly increased protein expression of HMGA1 $(\mathrm{P}<0.05)$. In contrast with the let-7d-5p mimic group, the protein expression of HMGA1 was significantly reduced in the let-7d-5p mimic + siHMGA1 + Tenovin-1 group $(\mathrm{P}<0.05)$. Compared with the let-7d-5p inhibitor group, the let-7d-5p inhibitor + siHMGA1 group exhibited significantly reduced protein expression of HMGA1 $(\mathrm{P}<0.05)$. Thus, the aforementioned results demonstrated that cells transfected with let-7d-5p mimic and siHMGA1 exhibited significantly elevated protein expression of p21, Bax, p27 and p53 ${ }^{\mathrm{wt}}$ and significantly reduced protein expression of p53 ${ }^{\text {mut }}$, PCNA, CDK2, MMP2, MMP9, Bcl-2 and HMGA1.

\section{Discussion}

$\mathrm{OC}$ is a lethal malignancy with various histopathological characteristics and biological behaviors, and with a $<40 \%$ overall remission rate at all stages (29). OC progression includes a series of events, including cancer cell EMT, migration, invasion and angiogenesis (30). Loss of let-7d activation may elevate Ras expression levels, and enhance productive viral infections and the death of cancer cells associated with apoptosis (31). The present study investigated the role of let-7d-5p as a significant disease modifying miR in OC. It was observed that let-7d-5p negatively regulated HMGA1, thus repressing OC cell proliferation, and promoting cell apoptosis and chemosensitivity by blocking the p53 signaling pathway.

Initially, based on the target prediction program and the dual luciferase activity determination, it was determined that HMGA1 was a target gene of let-7d-5p and that elevated let-7d-5p silenced HMGA1. HEK293T cells seldom express the endogenous receptor that extracellular ligands require and can be easily transfected, which are common cell lines for investigating exogenous genes and suitable for the present study. Besides, the present study did not involve the association between HMGA1 and OC cell growth $(32,33)$. It was determined that let-7d-5p expression was low in OC tissues and further reduced in cell lines OVCAR-3 and A2780. Family members of let-7d, including let-7d, were detectable in OC specimens, whose expression levels were negatively associated with the mRNA expression of HMGA2 (34). Additionally, the negative regulation of the let-7 family of HMGA expression was analyzed by previous researchers in oral squamous cell carcinoma (35). It has been revealed that let-7d expresses at a reduced level in malignant tissues, compared with benign prostate tissues (36). Furthermore, let-7d expression has been reported to be reduced in OC tissues, compared with adjacent normal tissues (37). Downregulated let-7d expression has also been reported to induce the EMT of epithelial cells in vitro and in vivo, and increase collagen deposition in lungs in vivo (38). According to the study by Kobayashi et al (39), discordant exosomal sequestration of let-7 miRNA is associated with the invasion ability of OC cells. These results were consistent with the present results demonstrating that HMGA1 is negatively regulated by let-7d-5p and that let-7d-5p is expressed poorly in OC tissues.

Additionally, it was determined that HMGA1 is highly expressed in OC and silenced HMGA1 was associated with enhanced apoptosis and chemosensitivity, and inhibited proliferation of OC cells. HMGA1 exhibits increased levels in epithelial OC tissues in comparison with healthy control specimens, and specimens in the $\mathrm{G}_{3}$ phase have increased HMGA1 expression, compared with those in the $\mathrm{G}_{1} / \mathrm{G}_{2}$ phase (18). An elevated HMGA1 protein level was positively associated with lymph node metastasis, the clinical stage, triple-negative breast cancer and tumor size in patients with breast cancer (40). Silencing of HMGA1 has also been demonstrated to inhibit metastases formation in vivo as well as invasion and migration in vitro in basal-like breast cancer cell lines (41). Silenced HMGA1 also suppresses cell growth in OC OVCAR cells and induces reduced cellular resistance to chemotherapeutic agents, while overexpressed HMGA1 in adherent OC cells elevates cellular resistance to chemotherapeutic agents in vitro (19). Furthermore, a previous study demonstrated that transfection with pcDNA6.2GW-let-7d to suppress the expression of HMGA2 caused alterations of the phenotype of IGROV1 cells exhibited by a reduced proliferative activity and increased cell apoptosis, which is in line with the results of the present study (17). In the present, it can be inferred that HMGA1 is highly expressed in OC and HMGA1 silencing contributed to promoting apoptosis and chemosensitivity, while inhibiting proliferation of OC cells.

Furthermore, it was determined that let-7d-5p may act as a tumor suppressor in $\mathrm{OC}$ via activating the $\mathrm{p} 53$ signaling pathway, which is reflected by its effect on restoration of cell apoptosis and chemosensitivity to cisplatin, and inhibition of cell proliferation. A previous study reported that overexpression of let-7d can effectively reverse the phenotype of EMT, accompanied by blocked migration and upregulated chemosensitivity in oral cancer by generating 
$\mathrm{ALDH}^{+}$cells (13). let-7d stimulates cancer inhibition induced by radiation, thereby enhancing the effects of synergistic radiotherapy on the renewal of stem cells (14). let-7d also inhibits cell growth, metastasis and macrophage infiltration through targeting collagen, type III, $\alpha 1$ and C-C motif chemokine ligand 7 in renal cell carcinoma (42). Additionally, p53 can activate cell-cycle arrest and cell apoptosis, when it is in a stable state, mediate apoptotic response and affect cisplatin resistance in OC $(43,44)$. Furthermore, p53 mutation is known as a genetic event that exists in OC and associates notably with resistance to platinum-based chemotherapy (45). c-Myc was confirmed to be a negative target gene of let-7d and knocking down c-Myc sensitized OC cells to 7-difluoromethoxyl-5,4'-di-n-octylgenistein, a novel synthetic genistein analogue that suppressed phosphoinositide 3-kinase (PI3K)/AKT signaling (37), while p53 is the downstream of PI3K/Akt signaling pathway (46). Silencing HMGA1 in tumor stem cells can significantly inhibit the activation of tumor stem cells, and reduce the efficiency of self-renewal and spheroidization, which may be achieved by regulating p53 (20). HMGA1 silencing can also significantly inhibit the proliferation of breast cancer cells, which may be associated with the p53 signaling pathway (41). Thus, the aforementioned results are consistent with the present data, which demonstrated that overexpression of let-7d-5p enhances chemosensitivity to cisplatin and apoptosis, while it inhibits proliferation in $\mathrm{OC}$ cells by activating the p53 signaling pathway.

In conclusion, the present study indicates that let-7d-5p activated the p53 signaling pathway by silencing HMGA1, thus promoting cell apoptosis and chemosensitivity to cisplatin while suppressing proliferation in OC cells. These data may provide novel ideas for future $\mathrm{OC}$ treatments. However, due to the limited time, space and study subjects, the present study was not comprehensive and may be insufficient on its own. It is expected that further studies involving the mechanism of let-7d-5p, HMGA1 and the p53 signaling pathway on chemotherapies for treatment of $\mathrm{OC}$ will be conducted in the future.

\section{Acknowledgements}

Not applicable.

\section{Funding}

This study was supported by the Science and Technology Public Relations Project of Henan Provincial Science and Technology Department (grant no. 162102310131).

\section{Availability of data and materials}

The datasets used and/or analyzed during the current study are available from the corresponding author on reasonable request.

\section{Authors' contributions}

YNC and CCR designed the study. LY, MMN and YMX collated the data, designed and developed the database, conducted data analyses and produced the initial draft of the manuscript. FZ and YL contributed to drafting the manuscript. All authors have read and approved the final submitted manuscript.

\section{Ethics approval and consent to participate}

The protocol was approved by the Ethics Committee of the Third Affiliated Hospital of Zhengzhou University (Zhengzhou, China). Written informed consent was obtained from the patients or patients' family.

\section{Patient consent for publication}

Written informed consent was obtained from the patients or patients' family.

\section{Competing interests}

The authors declare that they have no competing interests.

\section{References}

1. Tew WP: Ovarian cancer in the older woman. J Geriatr Oncol 7: 354-361, 2016.

2. Lin HW, Tu YY, Lin SY, Su WJ, Lin WL, Lin WZ, Wu SC and Lai YL: Risk of ovarian cancer in women with pelvic inflammatory disease: A population-based study. Lancet Oncol 12: 900-904, 2011.

3. Kurman RJ and Shih IeM: The origin and pathogenesis of epithelial ovarian cancer: A proposed unifying theory. Am J Surg Pathol 34: 433-443, 2010.

4. Colombo N: Optimizing treatment of the partially platinum-sensitive ovarian cancer patient. Future Oncol 9 (Suppl): 19-23, 2013.

5. Gershenson DM: Treatment of ovarian cancer in young women. Clin Obstet Gynecol 55: 65-74, 2012.

6. Bell D, Berchuck A, Birrer M, Chien J, Cramer DW, Dao F, Dhir R, DiSaia P, Gabra H, Glenn P, et al; Cancer Genome Atlas Research Network: Integrated genomic analyses of ovarian carcinoma. Nature 474: 609-615, 2011.

7. Jelovac D and Armstrong DK: Recent progress in the diagnosis and treatment of ovarian cancer. CA Cancer J Clin 61: 183-203, 2011.

8. Bookman MA: First-line chemotherapy in epithelial ovarian cancer. Clin Obstet Gynecol 55: 96-113, 2012.

9. Jacobs IJ, Menon U, Ryan A, Gentry-Maharaj A, Burnell M, Kalsi JK, Amso NN, Apostolidou S, Benjamin E, Cruickshank D, et al: Ovarian cancer screening and mortality in the UK Collaborative Trial of Ovarian Cancer Screening (UKCTOCS): A randomised controlled trial. Lancet 387: 945-956, 2016.

10. Bagnoli M, Pignata S and Mezzanzanica D: A miRNA signature assessing ovarian cancer prognosis. Oncoscience 3: 308-310, 2016.

11. Kan CW, Howell VM, Hahn MA and Marsh DJ: Genomic alterations as mediators of miRNA dysregulation in ovarian cancer. Genes Chromosomes Cancer 54: 1-19, 2015.

12. Wang Z, Lin S, Li JJ, Xu Z, Yao H, Zhu X, Xie D, Shen Z, Sze J, $\mathrm{Li}$ K, et al: MYC protein inhibits transcription of the microRNA cluster MC-let-7a-1 let-7d via noncanonical E-box. J Biol Chem 286: 39703-39714, 2011.

13. Chang CJ, Hsu CC, Chang CH, Tsai LL, Chang YC, Lu SW, $\mathrm{Yu} \mathrm{CH}$, Huang HS, Wang JJ, Tsai $\mathrm{CH}$, et al: Let-7d functions as novel regulator of epithelial-mesenchymal transition and chemoresistant property in oral cancer. Oncol Rep 26: 1003-1010, 2011.

14. Sun H, Ding C, Zhang H and Gao J: Let-7 miRNAs sensitize breast cancer stem cells to radiation-induced repression through inhibition of the cyclin D1/Akt1/Wnt1 signaling pathway. Mol Med Rep 14: 3285-3292, 2016.

15. Rohm B, Holik AK, Kretschy N, Somoza MM, Ley JP, Widder S, Krammer GE, Marko D and Somoza V: Nonivamide enhances miRNA let-7d expression and decreases adipogenesis PPAR $\gamma$ expression in 3T3-L1 cells. J Cell Biochem 116: 1153-1163, 2015. 
16. García-Vázquez R, Gallardo Rincón D, Ruiz-García E, Meneses García A, Hernández De La Cruz ON, Astudillo-De La Vega H, Isla-Ortiz D, Marchat LA, Salinas-Vera YM, Carlos-Reyes Á, et al: let-7d-3p is associated with apoptosis and response to neoadjuvant chemotherapy in ovarian cancer. Oncol Rep 39: 3086-3094, 2018.

17. Ye H, Chen J, Huang X, Guo A and Hao P: Construction of let-7d expression vector and its inhibitory effect on HMGA2 and ras expression in human ovarian cancer cells in vitro. Nan Fang Yi Ke Da Xue Xue Bao 32: 1752-1757, 2012 (In Chinese).

18. Zhou J, Xie M, He H, Shi Y, Luo B, Gong G, Li J, Wang J, $\mathrm{Wu} \mathrm{X}$ and Wen J: Increases urinary HMGA1 in serous epithelial ovarian cancer patients. Cancer Biomark 15: 325-331, 2015.

19. Kim DK, Seo EJ, Choi EJ, Lee SI, Kwon YW, Jang IH, Kim SC, Kim KH, Suh DS, Seong-Jang K, et al: Crucial role of HMGA1 in the self-renewal and drug resistance of ovarian cancer stem cells. Exp Mol Med 48: e255, 2016.

20. Puca F, Colamaio M, Federico A, Gemei M, Tosti N, Bastos AU, Del Vecchio L, Pece S, Battista S and Fusco A: HMGA1 silencing restores normal stem cell characteristics in colon cancer stem cells by increasing p53 levels. Oncotarget 5: 3234-3245, 2014.

21. Aiello A, Pandini G, Sarfstein R, Werner H, Manfioletti G Vigneri $\mathrm{R}$ and Belfiore A: HMGA1 protein is a positive regulator of the insulin-like growth factor-I receptor gene. Eur J Cancer 46: 1919-1926, 2010.

22. Fraser JA, Madhumalar A, Blackburn E, Bramham J, Walkinshaw MD, Verma C and Hupp TR: A novel p53 phosphorylation site within the MDM2 ubiquitination signal: II. a model in which phosphorylation at SER269 induces a mutant conformation to p53. J Biol Chem 285: 37773-37786, 2010

23. Stegh AH: Targeting the p53 signaling pathway in cancer therapy - the promises, challenges and perils. Expert Opin Ther Targets 16: 67-83, 2012.

24. Woo MG, Xue K, Liu J, McBride $H$ and Tsang BK: Calpain-mediated processing of p53-associated parkin-like cytoplasmic protein (PARC) affects chemosensitivity of human ovarian cancer cells by promoting p53 subcellular trafficking. J Biol Chem 287: 3963-3975, 2012.

25. Wilking MJ, Singh C, Nihal M, Zhong W and Ahmad N: SIRT1 deacetylase is overexpressed in human melanoma and its small molecule inhibition imparts anti-proliferative response via p53 activation. Arch Biochem Biophys 563: 94-100, 2014.

26. Marx C, Marx-Blümel L, Lindig N, Thierbach R, Hoelzer D, Becker S, Wittig S, Lehmann R, Slevogt H, Heinzel T, et al: The sirtuin 1/2 inhibitor tenovin-1 induces a nonlinear apoptosis-inducing factor-dependent cell death in a p53 null Ewing's sarcoma cell line. Invest New Drugs 36: 396-406, 2018.

27. Grbesa I, Pajares MJ, Martínez-Terroba E, Agorreta J, Mikecin AM, Larráyoz M, Idoate MA, Gall-Troselj K, Pio R and Montuenga LM: Expression of sirtuin 1 and 2 is associated with poor prognosis in non-small cell lung cancer patients. PLoS One 10: e0124670, 2015.

28. Ayuk SM, Abrahamse H and Houreld NN: The role of photobiomodulation on gene expression of cell adhesion molecules in diabetic wounded fibroblasts in vitro. J Photochem Photobiol B 161: 368-374, 2016.

29. Garces AH, Dias MS, Paulino E, Ferreira CG and de Melo AC: Treatment of ovarian cancer beyond chemotherapy: Are we hitting the target? Cancer Chemother Pharmacol 75: 221-234, 2015.

30. Gu A, Jie Y, Yao Q, Zhang Y and Mingyan E: Slug is associated with tumor metastasis and angiogenesis in ovarian cancer. Reprod Sci 24: 291-299, 2017.
31. Nuovo GJ, Garofalo M, Valeri N, Roulstone V, Volinia S, Cohn DE, Phelps M, Harrington KJ, Vile R, Melcher A, et al: Reovirus-associated reduction of microRNA-let-7d is related to the increased apoptotic death of cancer cells in clinical samples. Mod Pathol 25: 1333-1344, 2012.

32. Anfray C, Dong B, Komaty S, Mintova S and Valable S: Acute toxicity of silver free and encapsulated in nanosized zeolite for eukaryotic cells. ACS Appl Mater Interfaces 9: 13849-13854, 2017.

33. Milatz S, Himmerkus N, Wulfmeyer VC, Drewell H, Mutig K, Hou J, Breiderhoff T, Müller D, Fromm M, Bleich M, et al: Mosaic expression of claudins in thick ascending limbs of Henle results in spatial separation of paracellular $\mathrm{Na}^{+}$and $\mathrm{Mg}^{2+}$ transport. Proc Natl Acad Sci USA 114: E219-E227, 2017.

34. Yang J,Zhang Q, Dong JQ, Chang XH and He XJ: Overexpression of high mobility group A2 and its correlation with microRNA let-7 family in serous ovarian cancers. Beijing Da Xue Xue Bao Yi Xue Ban 44: 749-754, 2012 (In Chinese).

35. Sterenczak KA, Eckardt A, Kampmann A, Willenbrock S, Eberle N, Länger F, Kleinschmidt S, Hewicker-Trautwein M, Kreipe $\mathrm{H}$, Nolte I, et al: HMGA1 and HMGA2 expression and comparative analyses of HMGA2, Lin28 and let-7 miRNAs in oral squamous cell carcinoma. BMC Cancer 14: 694, 2014.

36. Ramberg H, Alshbib A, Berge V, Svindland A and Taskén KA: Regulation of PBX3 expression by androgen and Let-7d in prostate cancer. Mol Cancer 10: 50, 2011.

37. Ning YX, Luo X, Xu M, Feng X and Wang J: Let-7d increases ovarian cancer cell sensitivity to a genistein analog by targeting c-Myc. Oncotarget 8: 74836-74845, 2017.

38. Pandit KV, Corcoran D, Yousef H, Yarlagadda M, Tzouvelekis A, Gibson KF, Konishi K, Yousem SA, Singh M, Handley D, et al: Inhibition and role of let-7d in idiopathic pulmonary fibrosis. Am J Respir Crit Care Med 182: 220-229, 2010.

39. Kobayashi M, Salomon C, Tapia J, Illanes SE, Mitchell MD and Rice GE: Ovarian cancer cell invasiveness is associated with discordant exosomal sequestration of Let-7 miRNA and miR-200. J Transl Med 12: 4, 2014.

40. Huang R, Huang D, Dai W and Yang F: Overexpression of HMGA1 correlates with the malignant status and prognosis of breast cancer. Mol Cell Biochem 404: 251-257, 2015.

41. Pegoraro S, Ros G, Piazza S, Sommaggio R, Ciani Y, Rosato A, Sgarra R, Del Sal G and Manfioletti G: HMGA1 promotes metastatic processes in basal-like breast cancer regulating EMT and stemness. Oncotarget 4: 1293-1308, 2013.

42. Su B, Zhao W, Shi B, Zhang Z, Yu X, Xie F, Guo Z, Zhang X, Liu J, Shen Q, et al: Let-7d suppresses growth, metastasis, and tumor macrophage infiltration in renal cell carcinoma by targeting COL3A1 and CCL7. Mol Cancer 13: 206, 2014.

43. Suh YA, Post SM, Elizondo-Fraire AC, Maccio DR, Jackson JG, El-Naggar AK, Van Pelt C, Terzian T and Lozano G: Multiple stress signals activate mutant p53 in vivo. Cancer Res 71: 7168-7175, 2011.

44. Wang J, Gao Q and Li Q: Adenovirus type 12 E1B 55-kilodalton oncoprotein promotes $\mathrm{p} 53$-mediated apoptotic response of ovarian cancer to cisplatin. Tumour Biol 36: 6569-6577, 2015.

45. Yuan Z, Cao K, Lin C, Li L, Liu HY, Zhao XY, Liu L, Deng HX, Li J, Nie CL, et al: The p53 upregulated modulator of apoptosis (PUMA) chemosensitizes intrinsically resistant ovarian cancer cells to cisplatin by lowering the threshold set by $\mathrm{Bcl}-\mathrm{x}(\mathrm{L})$ and Mcl-1. Mol Med 17: 1262-1274, 2011.

46. Zhang X, Wu H, Liu C, Tian J and Qu L: PI3K/Akt/p53 pathway inhibits reovirus infection. Infect Genet Evol 34: 415-422, 2015. 